\title{
Experimental Research and Numerical Simulation of Single Soil- Arc-Grounding-Fault in Distribution Networks
}

\author{
Haoran Chen $\left(\mathbb{D},{ }^{1}\right.$ Xin Lin, ${ }^{1}$ Guanhua $\mathrm{Li}^{2}{ }^{2}$ Jianyuan $\mathrm{Xu},{ }^{1}$ Hui $\mathrm{Li}^{3}$ and Shuai Wang ${ }^{2}$ \\ ${ }^{1}$ College of Electrical Engineering, Shenyang University of Technology, Shenyang 110870, China \\ ${ }^{2}$ Electric Power Research Institute, Liaoning Electric Power Co., Ltd., State Grid, Shenyang 110006, China \\ ${ }^{3}$ China Electric Power Research Institute, Wuhan 430074, China
}

Correspondence should be addressed to Haoran Chen; 20905005@zju.edu.cn

Received 26 August 2021; Revised 27 September 2021; Accepted 4 October 2021; Published 5 November 2021

Academic Editor: Deepak Kumar Jain

Copyright (c) 2021 Haoran Chen et al. This is an open access article distributed under the Creative Commons Attribution License, which permits unrestricted use, distribution, and reproduction in any medium, provided the original work is properly cited.

Among the distribution network faults, single-phase grounding faults have the greatest probability. The faults are often accompanied by arcs in the grounding point soil. This type of fault current has a small amplitude and seldom can obtain field record data. A soil arc grounding fault is tested on a realistic-distribution-network-experimental-platform (RDNEP), and it is concluded that the soil-arc-grounding-fault (SAGF) has three main characteristics: hysteresis, nonlinearity, and asymmetry. By comparing with the characteristics of common arc models, it is pointed out that common arc models cannot accurately fit the characteristics of SAGF. This paper proposes and establishes a double exponential function arc model. Through the comparison of simulation waveforms with experimental data, it is verified that the numerical simulation method proposed in this paper can simulate the development process of SAGF more accurately. Furthermore, the equivalence of RDNEP is verified on the real distribution network system (RDNS). On this basis, analyzed the arc characteristic changes of different SAGF development cycles. Finally, by studying the applicability of the proposed model in simulating ground faults in grass and gravel roads, it is verified that the model proposed in this paper has a strong generalization capability. The research has laid a theoretical foundation for a detection algorithm that is based on the characteristics of SAGF.

\section{Introduction}

Among the line faults in $10 \mathrm{kV}$ distribution networks, single line-to-ground faults (SLGF) account for the majority. At the end of the grounding point, soil often does not have a good dispersion channel like a grounding grid. In the process of ground current dissipating at the grounding point, it is often accompanied with soil arc phenomenon that called this type of fault a SAGF. Compared with arc grounding faults (AGF), SAGF has some unique properties. With the deepening of the research on grounding faults identification in distribution networks, research on fault detection, fault type identification, and fault location based on the characteristics of grounding arc has gradually become a hot research direction. Therefore, the establishment of a mathematical model that accurately describes the characteristics of the SAGF is an important basis for studying related issues [1-3].
For the simulation of single-phase arc-ground fault characteristics, the difficulty lies in accurately reproducing the dynamic changes in ground resistance, and this requires an accurate arc model. At present, the arc models used by scholars to study AGF in distribution networks are mainly black-box models that describe the external characteristics of the soil arc $[1,4]$. The commonly used black-box models are basically based on the improvements of the Mayr model [5], Cassie Model [6], Schwarz model [7], and Cybernetic model [8], and all the above models are established based on the heat balance equation. Reference [9] established a model based on the Mayr series fixed resistance to simulate the arc high-resistance ground fault, but the method of obtaining the model parameters was not given. The arc model established in Reference [10] is based on the Cybernetic arc model series fixed resistance, but it also does not give how the arc parameters are obtained. Reference [11] is 
based on solid dielectric breakdown theory to model highresistance ground fault nonlinear resistance, which is essentially a piecewise resistance model. . The models proposed in the above studies are all transplanted applications of the air arc model in the study of AGF.

Shiller et al. has related descriptions of the causes of SAGF and the characteristics of current dynamic changes [12]. One of the characteristics is the nonlinear change of fault current from small to large during the development of the fault; another characteristic is the asymmetry of the positive and negative half-waves of the current. This characteristic description is not comprehensive. The arc experiment simulated the soil arc between the electrodes, not the SAGF caused by the wire falling on the soil surface.

In order to describe the dynamic characteristics of the development of SAGF, there are currently two main solutions. One is achieved by using two DC sources connected antiparallel by means of two diodes, then series variable resistor. Two DC power supplies are set with different voltages to describe zero-rest characteristics, and variable impedance is used to describe the nonlinear characteristic of the development process [12-17]. Another solution is to use the arc model in the form of double variable resistance in series, one variable resistor is used to simulate the asymmetry of a single cycle, and the other variable resistor is used to simulate the nonlinear characteristic of the development process [18]. However, the characterization of the soil arc in the above research is not accurate.

The SAGF fault current is generally small and difficult to be detected, and it is rarely possible to obtain the fault field recording data. In this paper, for establishing an accurate SAGF model, conducted a SAGF experiment on a RDNEP. Analyzing the characteristics of SAGF and comparing it with the characteristics of common arc models, it is pointed out that common arc models cannot accurately describe the characteristics of SAGF. On this basis, an idea of the diffusion channel of a SAGF is proposed and established a double exponential function soil arc model based on current density considering ionization and nonionization regions. By comparing the simulation waveform with the experimental data, it is verified that the SAGF numerical simulation method proposed in this paper can simulate the characteristics of soil arc more accurately. Furthermore, the equivalence of RDNEP is verified on the RDNS. On this basis, it analyzed the arc characteristic changes of different SAGF development cycles. At last, by studying the applicability of the model proposed in this paper in simulating grassland and stone road grounding faults, it is obtained that the model proposed in this paper has a strong general use ability. It laid a theoretical foundation for subsequent research on detection algorithms based on soil arc characteristics.

\section{Experimental Work}

An experiment has been performed to measure the characteristics of a SAGF. The experiment was carried out on the RDNEP built by China Electric Power Research Institute (CEPRI).

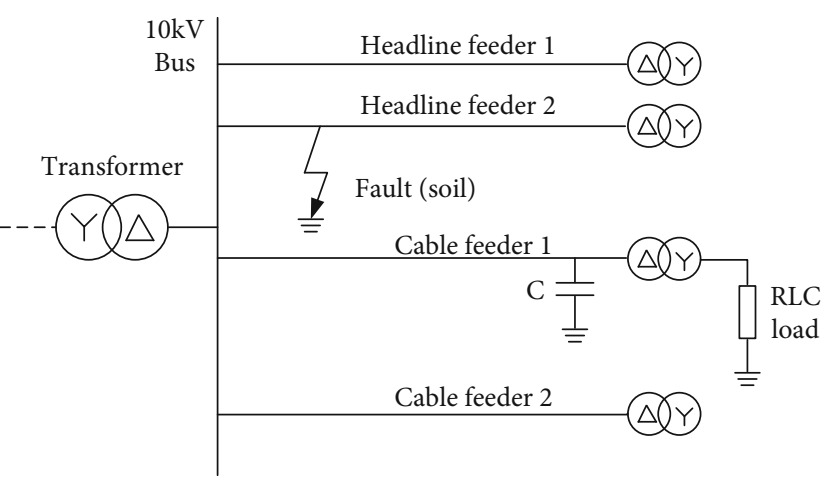

FIgURE 1: Topological structure of testing power system.

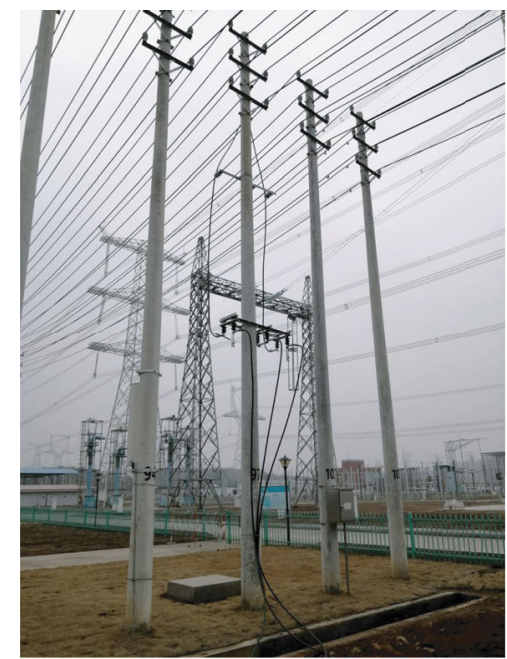

Fault Feeder

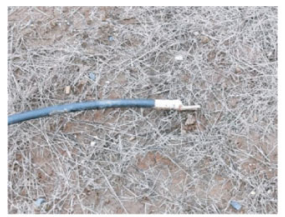

Before fault

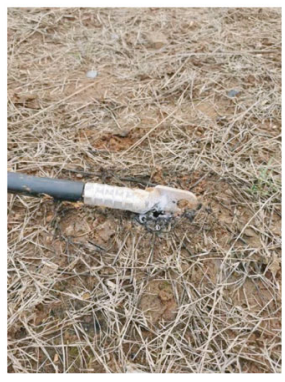

After fault
FIgURE 2: Schematic diagram of the experimental.

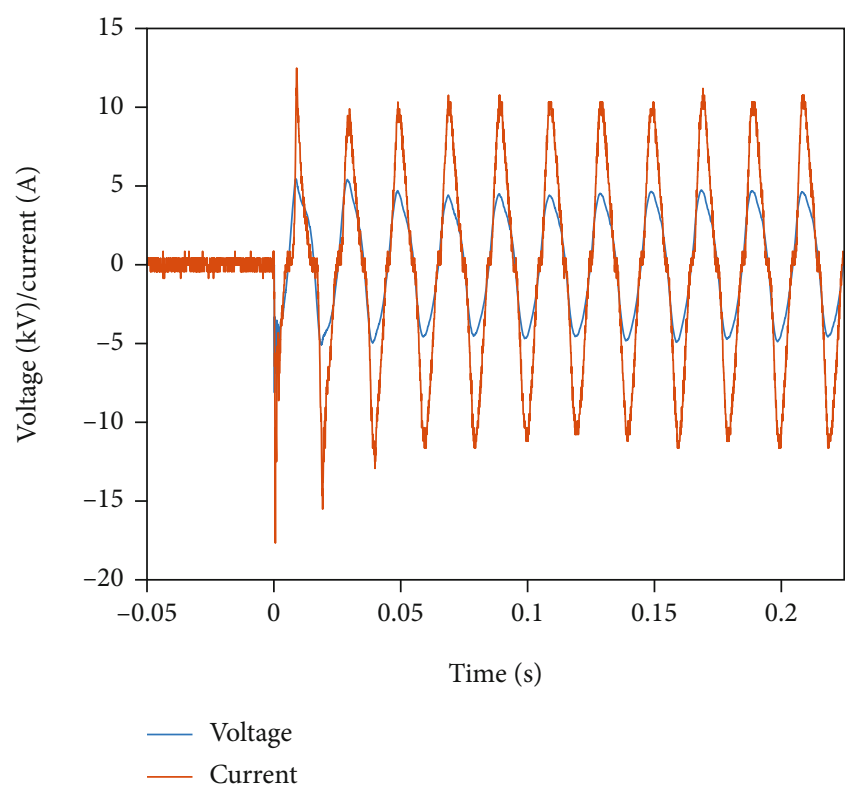

Figure 3: Curve of voltage and current of a SAFG. 


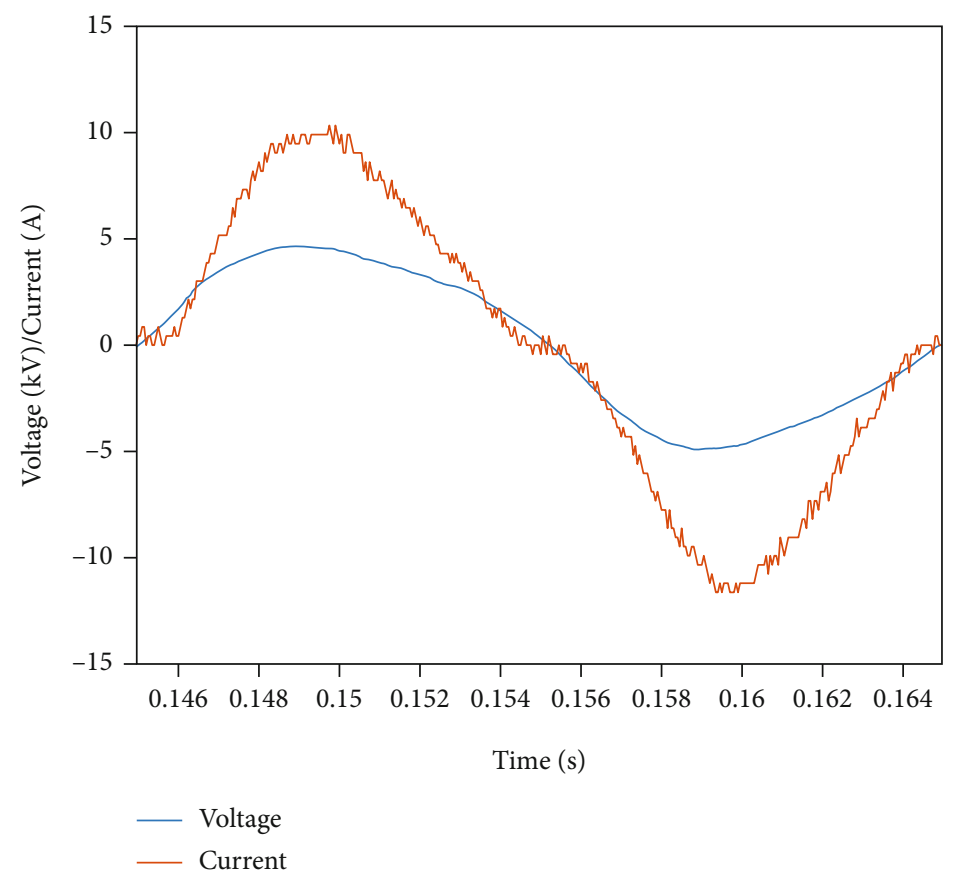

FIgURE 4: Single circle curve of voltage and current of a SAFG.

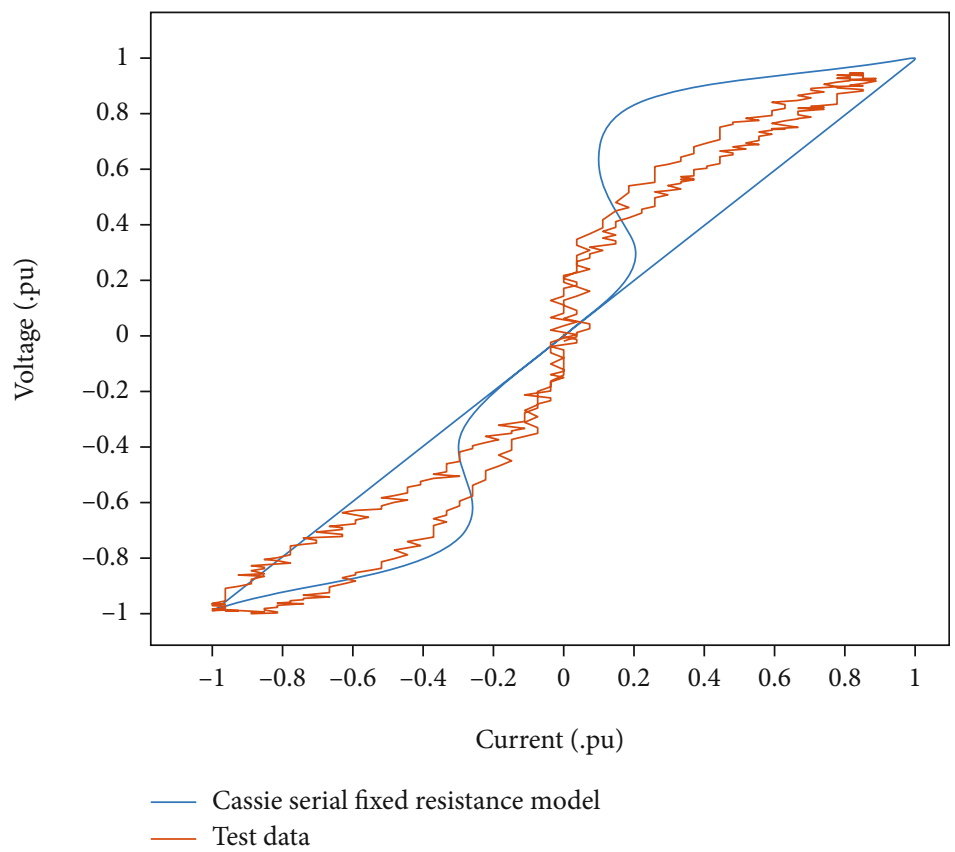

FIGURE 5: V/A characteristics of arc in serial with resistance.

2.1. RDNEP Set Up. The RDNEP uses a $220 / 10 \mathrm{kV}$ transformer as the platform power supply. The platform is equipped with four feeder lines, two $3.5 \mathrm{~km}$ true overhead lines, two $560 \mathrm{~m}$ cable lines, and capacitors are connected to each line to simulate a larger-scale distribution network. The end of the line is connected to the RLC adjustable load through a $10 / 0.4 \mathrm{kV}$ transformer. A total of 80 measurement and control devices realize all-round detection of the distribution network status. All equipment site layout drawings and parameters are indicated in Appendix.

2.2. Experimental and Results. Simulate a streamlined distribution network structure on RDNEP, the topological structure is shown in Figure 1. The platform consists of 4 


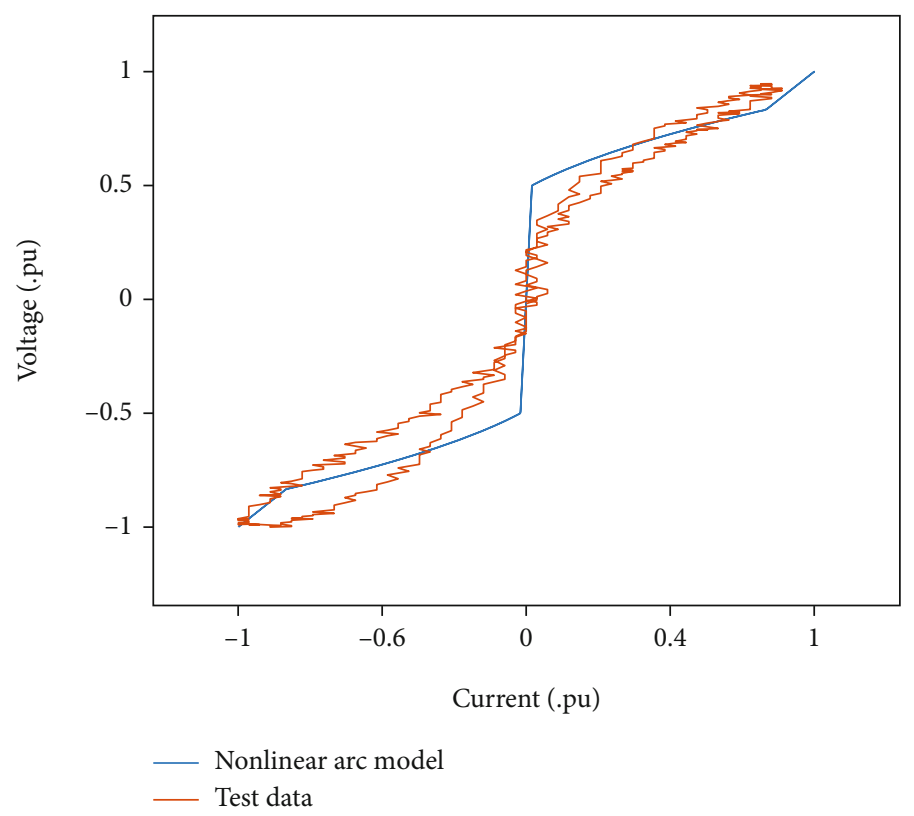

FIgURE 6: V/A characteristics of SDBHGF.

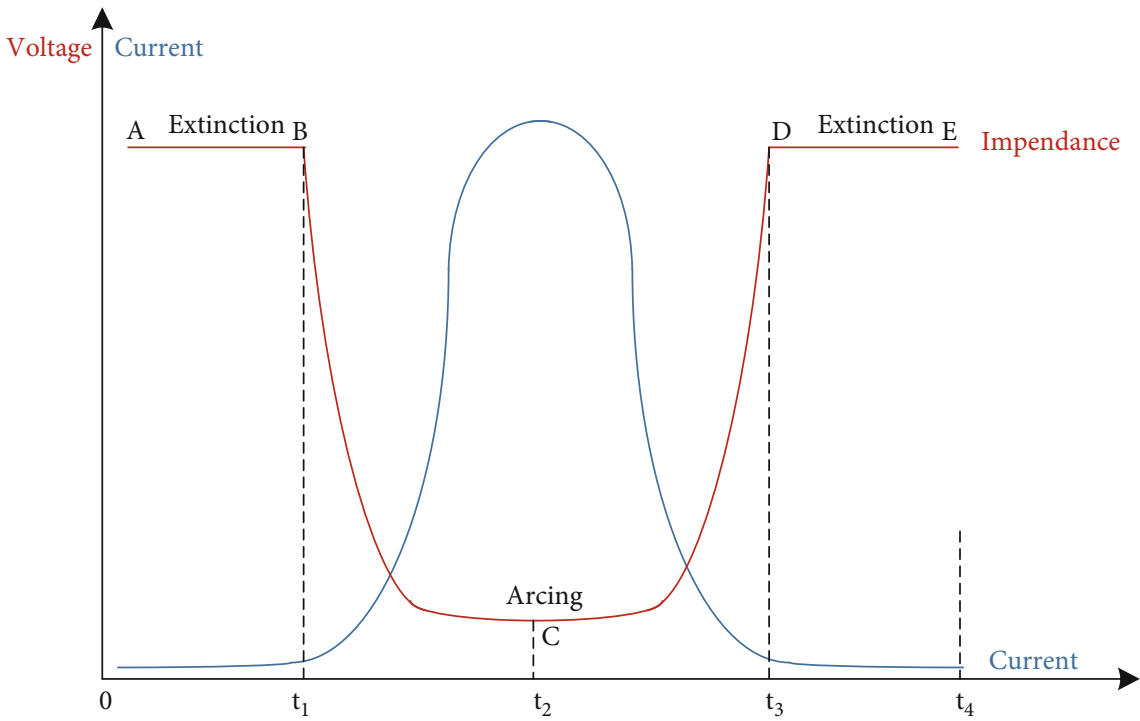

FIGURE 7: Schematic diagram of SAGF resistance.

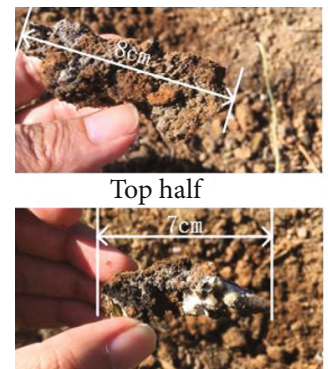

Bottom half

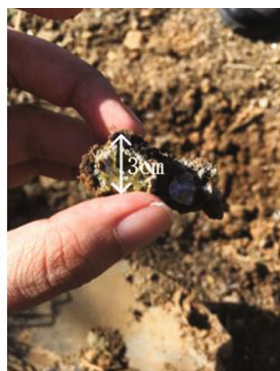

Diameter

Figure 8: $\mathrm{SiO}_{2}$ crystals after single-phase soil arc test.

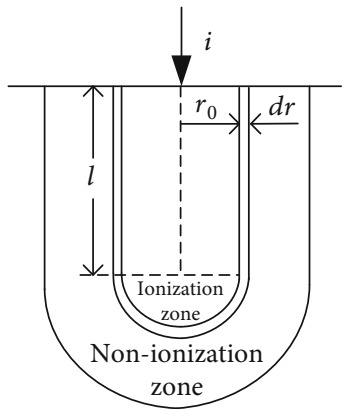

FIgURE 9: Schematic diagram of SAGF dispersion channel. 


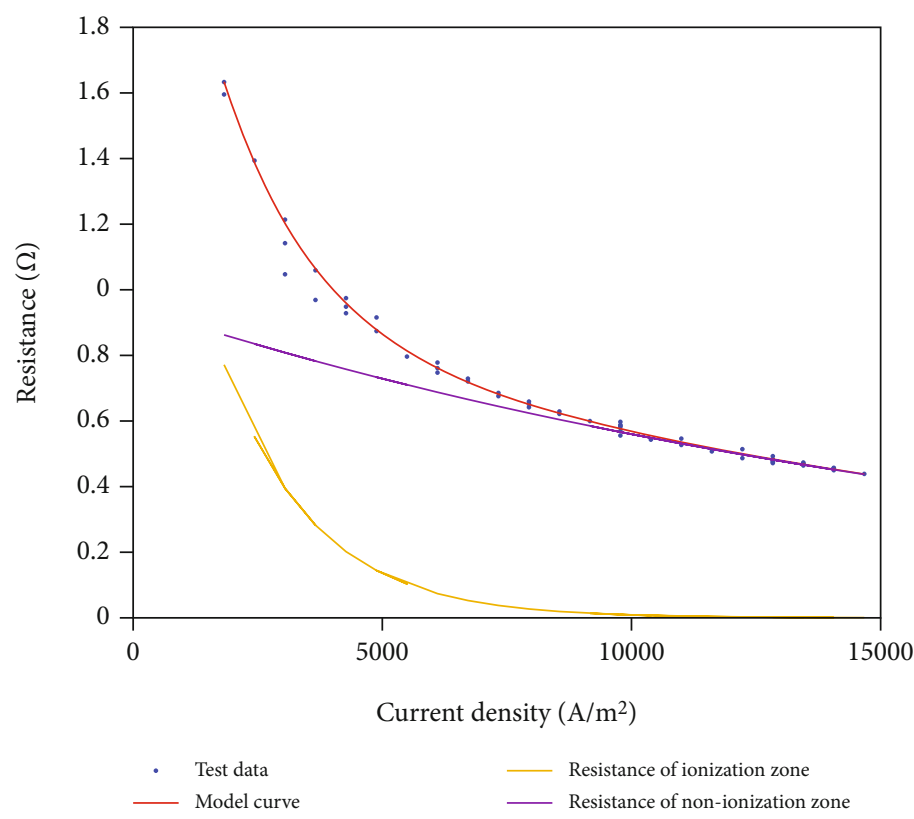

FIGURE 10: SAGF positive half-circle ionization process.

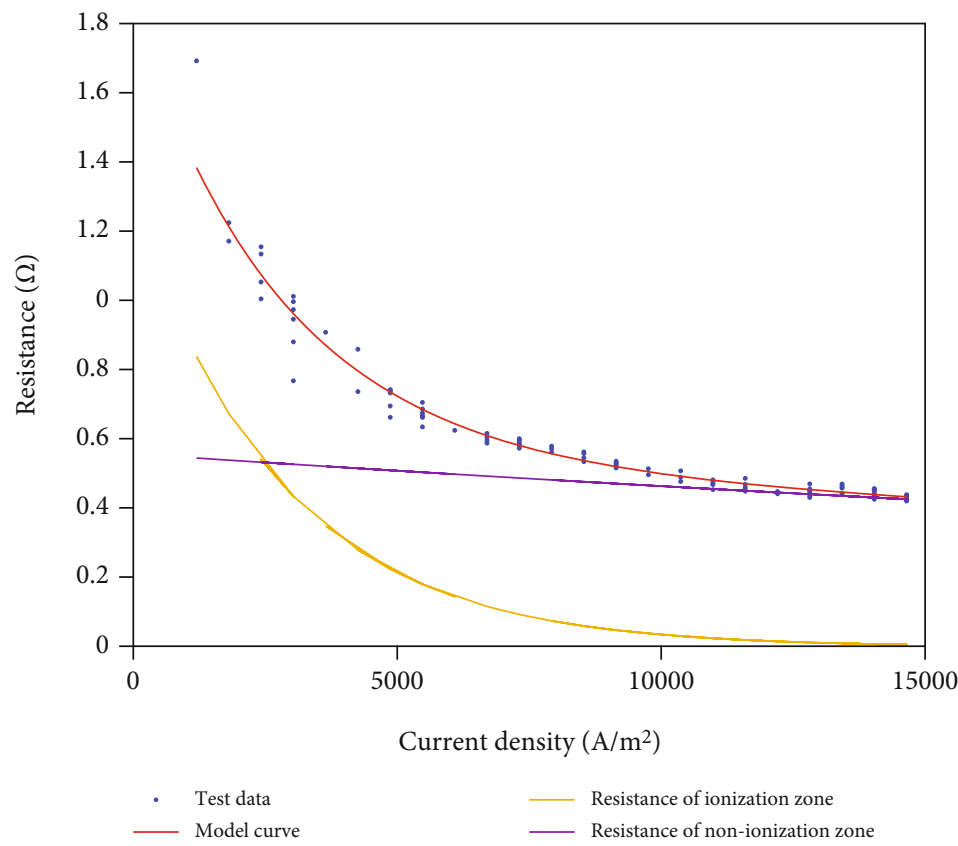

FIGURE 11: SAGF positive half-circle deionization process.

feeders, 2 overhead line feeders, and 2 cable feeders. Three capacitors are connected to the end of cable Feederl, the capacitance values $C=0.64 \mathrm{uF}$, respectively. Neutral point of the transformer is not grounded.

Place the faulty line on the surface of the soil ground through a piece of cable to simulate the state of the overhead line falling on the ground surface due to the fault, as shown in Figure 2.

Figure 3 shows the fault voltage and current waveforms at the grounding point when the fault occurs.
The arc current has an obvious zero-rest at the zero crossings of each half-cycle; it is a standard arc discharge characteristic. A single cycle is selected for further analysis. The voltage and current curves of this cycle are shown in Figure 4. The amplitude of the negative half circle current is obviously greater than the positive half circle, the voltage peak and current peak time are not synchronized, and the current peak phase lags the voltage peak phase.

Compared with air arc, SAFG has three main characteristics. 


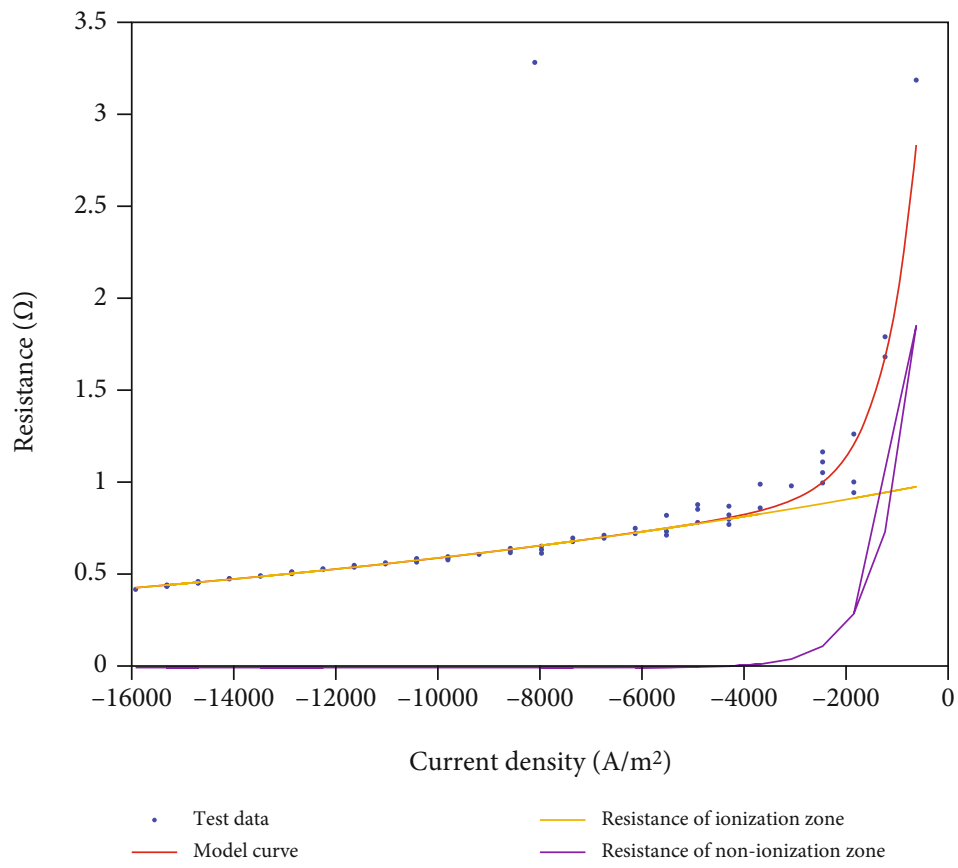

FIGURE 12: SAGF negative half-circle ionization process.

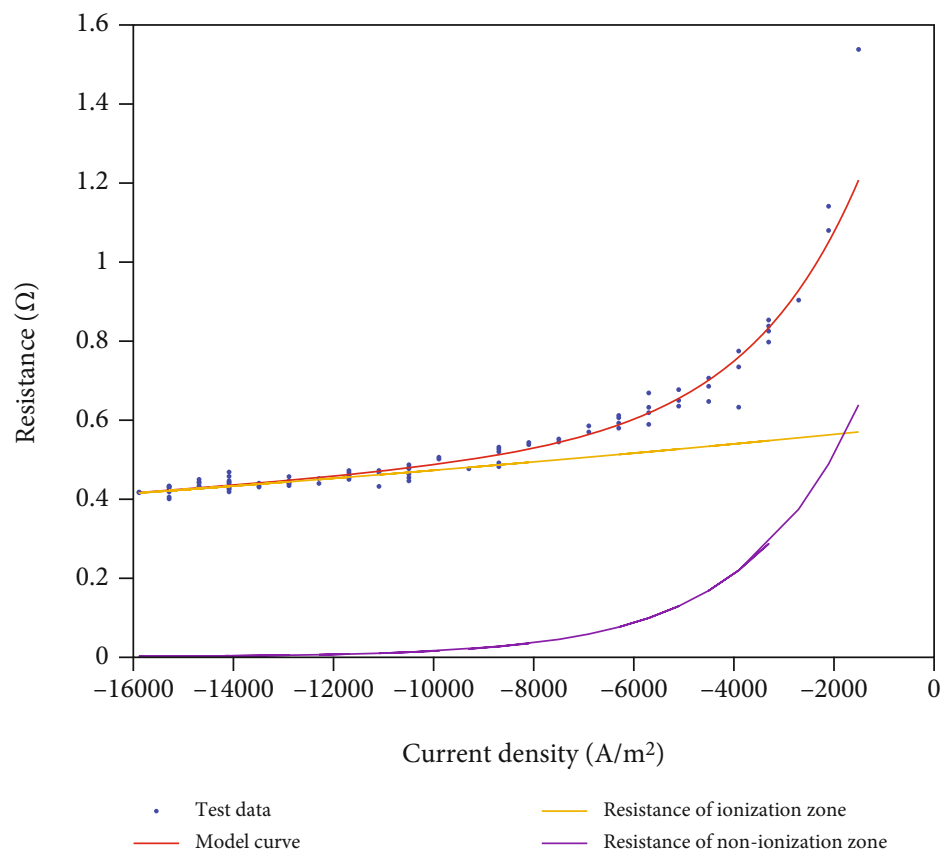

FIGURE 13: SAGF negative half-circle deionization process.

(1) Fault current phase lags behind voltage phase (hysteresis)

(2) The soil ionization rate is faster than the soil deionization rate (nonlinearity)

(3) The soil resistance of the negative half cycle is less than that of the positive half cycle (asymmetry)

\section{Results Analysis}

The commonly used arc models can only partially simulate SAFG characteristics and compare the V/A characteristics of some ground fault models and SAFG, including Cassie arc model [6], Cassie series fixed-resistance model, and high resistance grounding fault nonlinear resistance model based 
TABLE 1: Samples of times roman type sizes and styles.

\begin{tabular}{|c|c|c|c|c|}
\hline Parameter & $\begin{array}{l}\text { Positive half-wave } \\
\text { ionization process }\end{array}$ & $\begin{array}{l}\text { Positive half-wave } \\
\text { deionization process }\end{array}$ & $\begin{array}{l}\text { Negative half-wave } \\
\text { ionization process }\end{array}$ & $\begin{array}{l}\text { Negative half-wave } \\
\text { deionization process }\end{array}$ \\
\hline $\begin{array}{l}\text { Initial soil resistivity in ionization } \\
\text { zone } \rho_{0} / \Omega m\end{array}$ & 348 & 214 & 773 & 183 \\
\hline $\begin{array}{l}\text { Initial soil resistivity in nonionized } \\
\text { zone } \rho_{g} / \Omega \mathrm{m}\end{array}$ & 373 & 219 & 398 & 100 \\
\hline $\begin{array}{l}\text { Current density constant of } \\
\text { ionization process } \tau_{1} /\left(\mathrm{A} / \mathrm{m}^{2}\right)\end{array}$ & -1822 & -2792 & 6600 & 3747 \\
\hline $\begin{array}{l}\text { Temperature conductivity } \tau_{2} / \\
\left(\mathrm{A} / \mathrm{m}^{2}\right)\end{array}$ & -18885 & -54704 & 18681 & 49652 \\
\hline
\end{tabular}

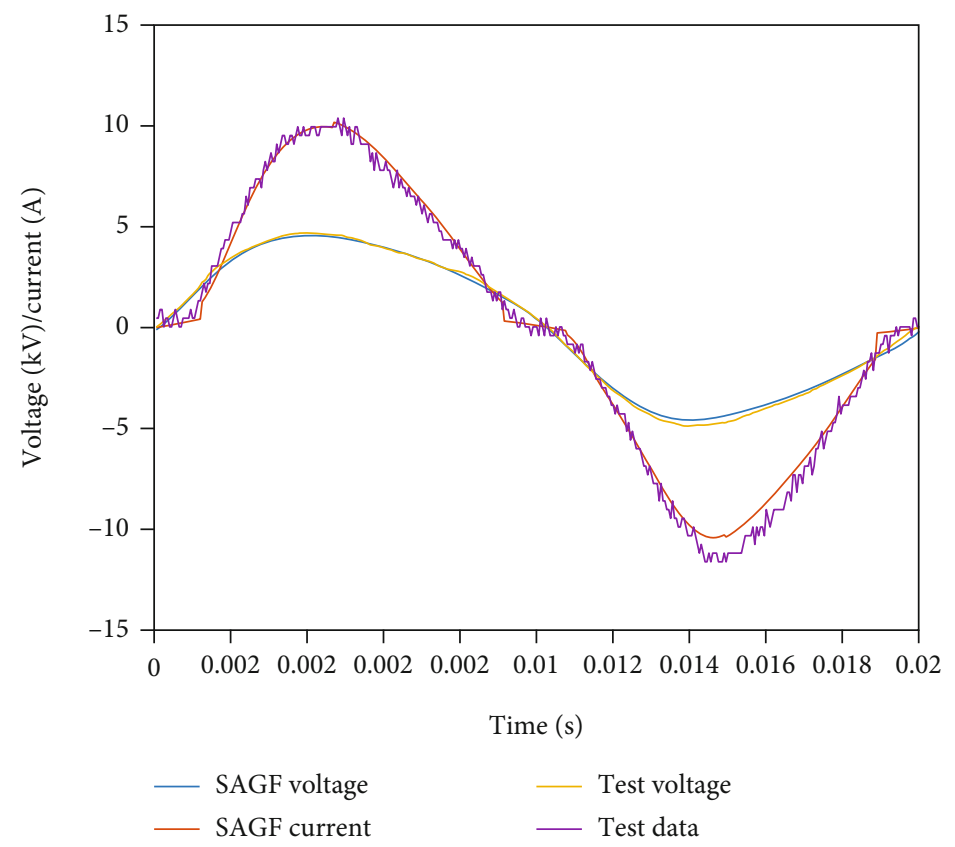

FIGURE 14: SAGF voltage and current comparison.

on solid dielectric breakdown theory (SDBHGF) [11]. All parameters are set for simulated test conditions.

3.1. Cassie Series Fixed-Resistance Arc Model. The Cassie arc model was proposed in 1939, and it considers the convection heat dissipation effect of the arc model. It is assumed that the energy dissipated from the electrode and the energy diffusion caused by the arc column change process can be ignored, and as the energy changes, the larger the arc column cross-sectional area, the greater the energy diffusion speed. Equation (1) is its mathematical model.

$$
\frac{1}{g} \frac{d g}{d t}=\frac{d \ln g}{d t}=\frac{1}{\tau_{c}}\left(\frac{E^{2}}{E_{c}^{2}}-1\right),
$$

where $g$ is the conductance of the arc; $t$ is the time; $\tau_{c}$ is time constant; $E$ is the electric potential per unit length of the arc, and $E_{c}$ is the potential gradient constant. As in (1), when the voltage exceeds a certain threshold, the arc ignites, and conductance increases exponentially; when the voltage decreases to reach the electric field strength $E=E_{c}$, the arc is in a steady state.

Figure 5 is the V/A characteristic curve when Cassie is connected in series with resistors. Due to the linear resistance, the voltage and current basically reach the maximum at the same time, and this does not match the hysteresis characteristic of SAFG. Before the current (or voltage) crosses the zero points, the V/A characteristic is mainly affected by the linear resistance, the linearity is basically maintained, and this does not match the nonlinearity characteristic. And obviously, the positive and negative halfwaves of this kind of models are symmetrical.

3.2. SDBHGF Model. The SDBHGF model is based on the principle of electrical breakdown of solid media. The conductance of a solid medium is mainly divided into ionic 


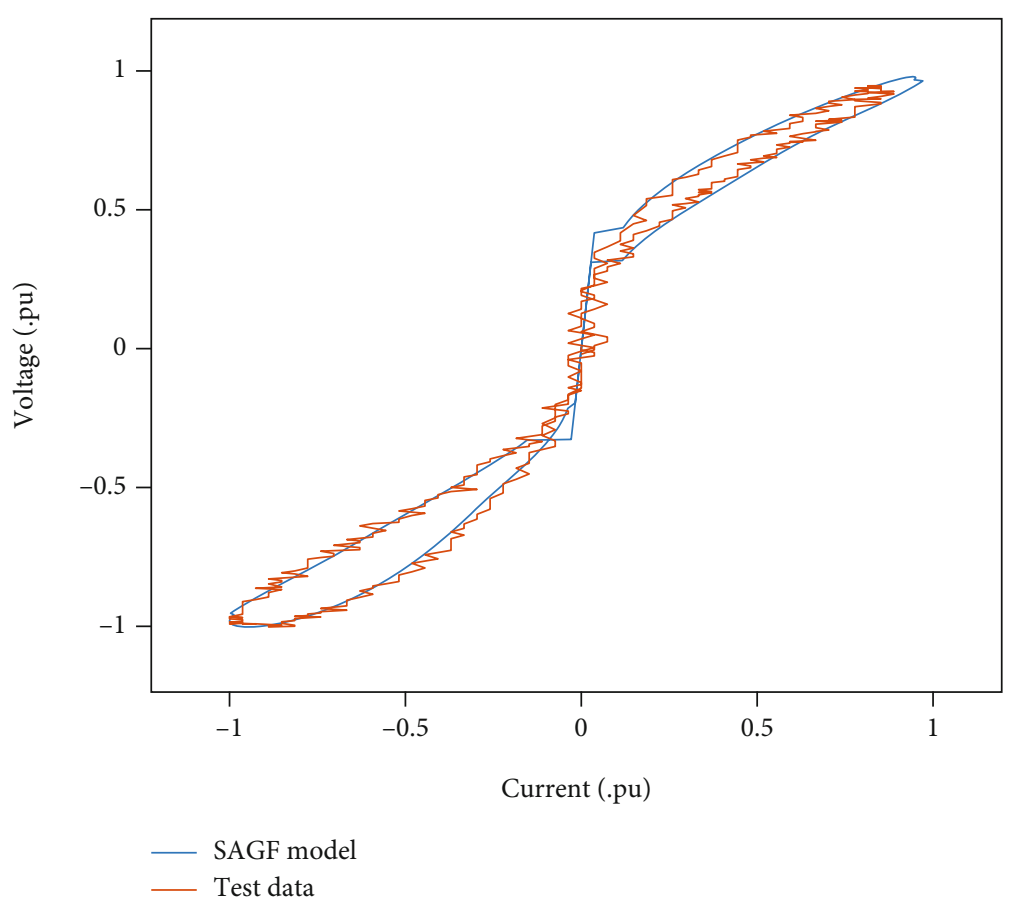

FIgURE 15: SAGF V/A characteristic comparison.

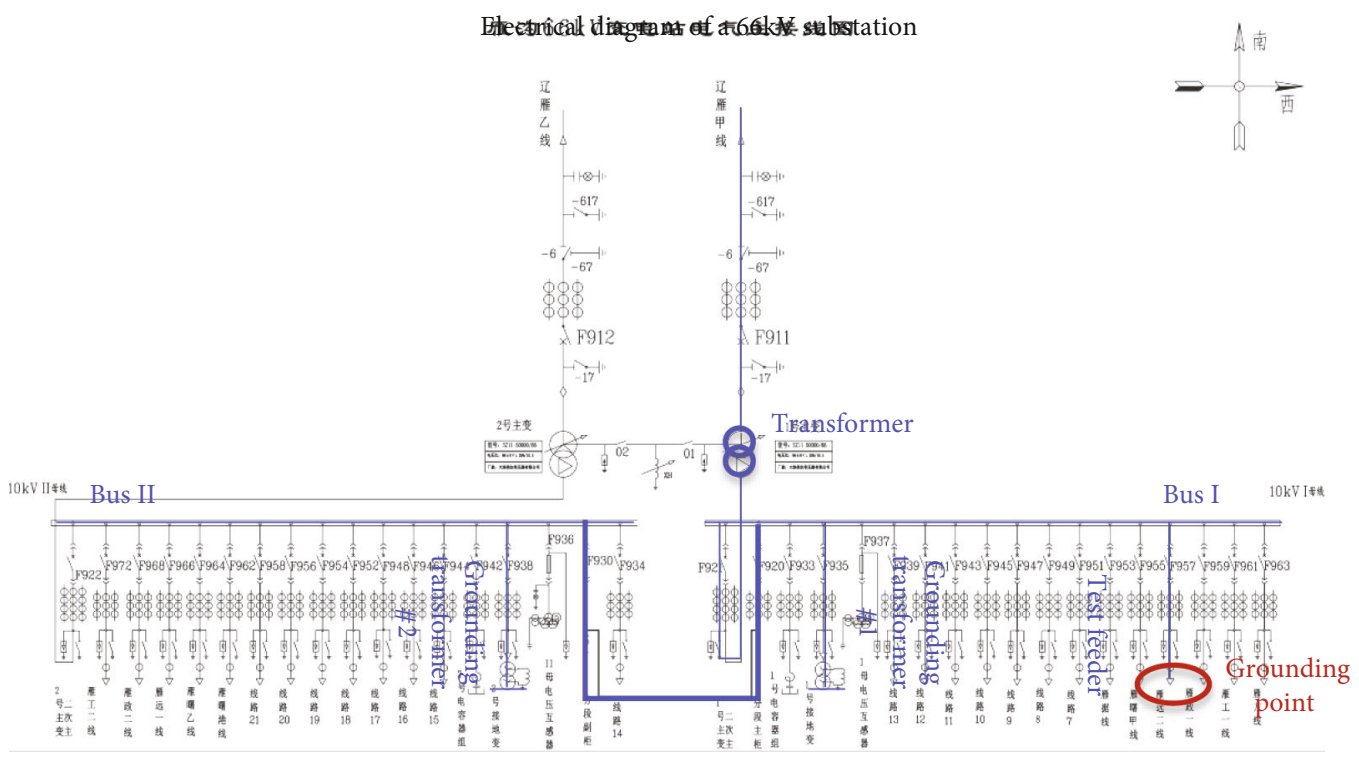

FiguRE 16: Schematic diagram of electrical wiring of test circuit.

conductance and electronic conductance. When the external electric field is low, it is mainly the ionic conductance that plays a role. At this period, the voltage and current are in a linear relationship. When the electric field gradually increases, within a certain range, the ion conductance still plays a major role, but the voltage and current show an exponential relationship. As the electric field continues to increase and exceeds a certain limit, the electronic conductance starts to take effect. At this period, the voltage and current are still in an exponen- tial relationship, but the conductance value is already large, and the equivalent resistance value is small. The model is divided into 3 sections, as in the following equation.

$$
g= \begin{cases}g_{1} & |u|<u_{1}, \\ 2 k_{1}|u|+k_{2} & u_{1}<|u|<u_{2}, \\ g_{2} & |u|>u_{2} .\end{cases}
$$




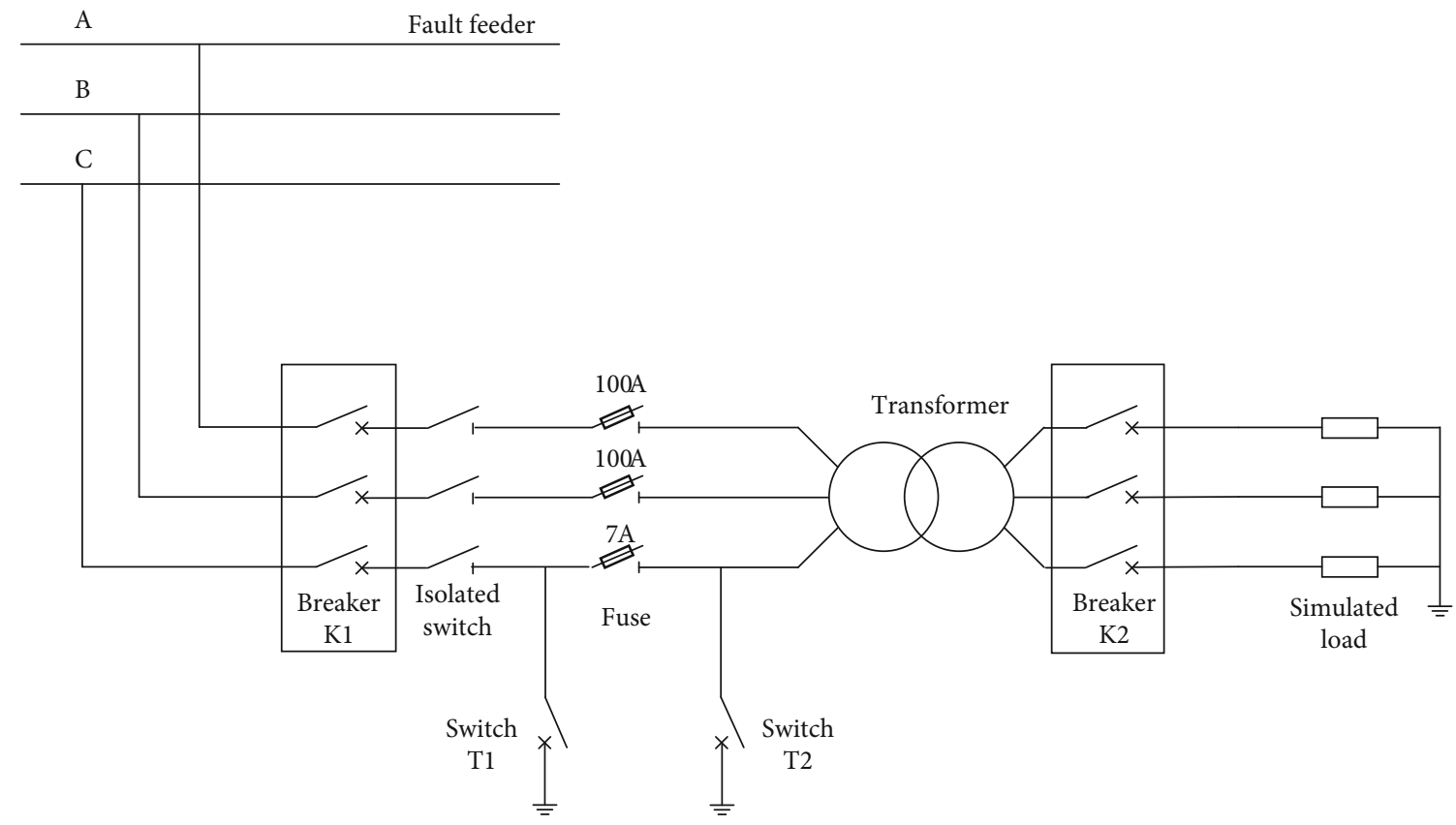

FIGURE 17: Schematic diagram of ground fault simulation platform.

The voltage and current of the SDBHGF model will reach the maximum at the same time, and it cannot simulate the nonlinearity and asymmetry of SAGF as shown in Figure 6.

Therefore, none of the abovementioned commonly used arc ground fault models can fully reflect the characteristics of SAGF, and the characteristic quantities of ground fault detection methods proposed based on the above models may fail when identifying a SAGF.

\section{SAGF Model}

The essence of the SAGF model is a variable grounding resistance, which is used to describe the process of resistance change during the arc from ignition to extinction. Figure 7 depicts a schematic diagram of the current and impedance changes for a complete arc development cycle. A B and $\mathrm{D} \sim \mathrm{E}$ stage for the arc zero rest stage, and $\mathrm{B} \sim \mathrm{D}$ for the arc from ignition to extinguish the process. The arcing period, from $t_{1}-t_{2}$, is the most critical, called soil ionization period, and other moments are called the arc extinguishing period.

As observed by the $\mathrm{SiO}_{2}$ crystal after the test in Figure 8, the ionization zone radius is about $0.015 \mathrm{~m}$, and the depth is about $0.15 \mathrm{~m}$ when the upper and lower parts are added together.

When the energy density of the injected current exceeds the critical value, soil ionization will occur. As the injected current increases, its resistivity is much lower than the initial resistivity of the soil. After the soil is ionized, a large amount of heat is generated. The soil in the ionization zone will be molten, and $\mathrm{SiO}_{2}$ will be precipitated. After the test, the soil near the grounding point is excavated and sampled. The cooled $\mathrm{SiO}_{2}$ crystal is almost cylindrical and perpendicular to the ground surface. The ionization current dispersion channel is cylindrical, as shown in Figure 9. A cylindrical shape with the grounding point as the center, radius $r_{0}$, and depth $\ell$, at the bottom of the cylinder is a hemisphere with radius $r_{0}$. Set this area as the ionization area. When the energy density of the injected current exceeds the critical value in this area, soil ionization will occur and soil properties will change. Outside the ionization zone is a nonionization zone. In this area, the soil is affected by the ionization heat effect, and the resistivity changes dynamically during the ground fault process.

Set the basic assumptions for the established soil arc model. Because the SAGF current is small, as observed in Figure 9, it is considered that the fault occurs in the shallow surface of the soil. It is assumed that the soil properties are uniform, that is, the resistivity of the soil in all directions and the result of the injection current. The resistivity change curve is consistent.

When the current density is greater than the critical value, the soil is ionized, and the soil resistivity decreases rapidly as the degree of ionization increases. This change state changes exponentially with the current density, as shown in (3).

$$
\rho_{1}=\rho_{0} \exp \frac{j}{\tau_{1}}
$$

where $\rho_{1}$ is the soil resistivity in the ionization zone, $\rho_{0}$ is the soil resistivity in the ionization zone when the current density $j=0, \tau_{1}$ is the current density constant of the 


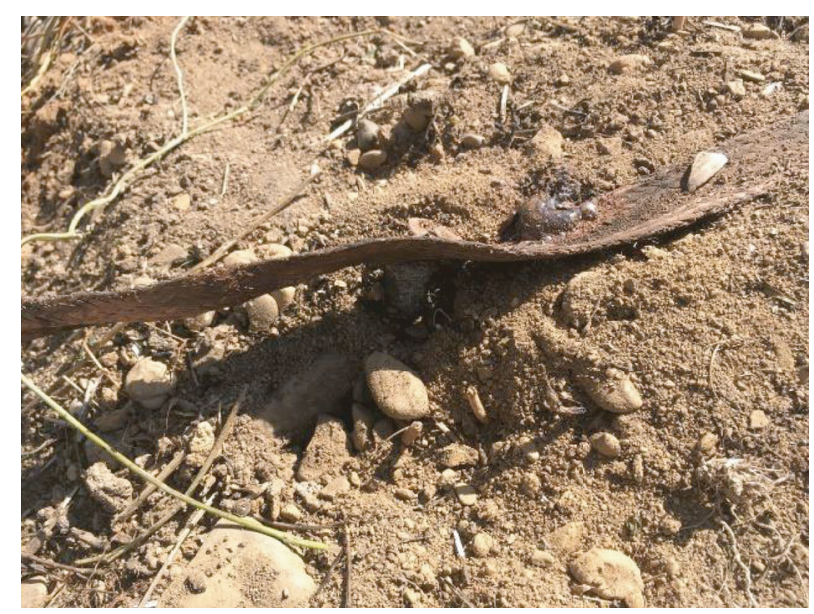

FIGURE 18: Grounding point after a SAGF test.

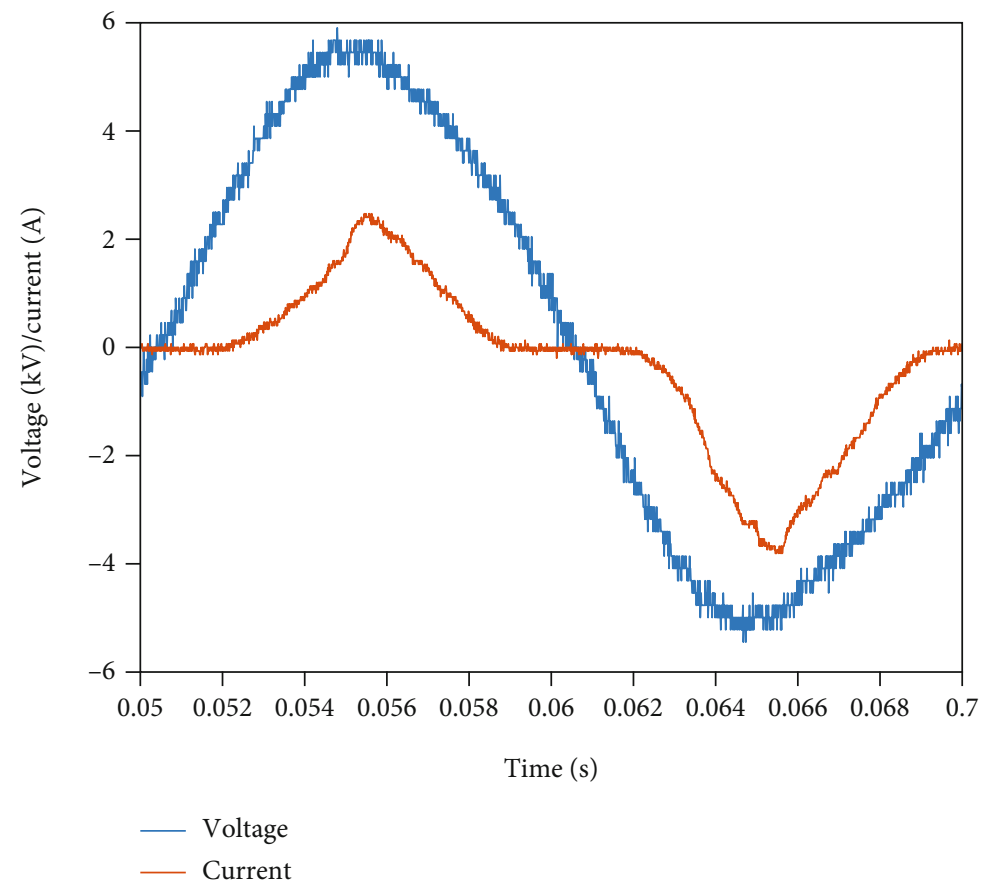

Figure 19: Curve of voltage and current of a SAFG.

ionization process, and the current density is a function of current.

$$
j=\frac{i}{\pi r^{2}},
$$

where $r$ is the radial distance of the ionization zone, and the resistance of the ionization zone can be expressed as the following equation.

$$
R_{1}=\frac{\rho_{1}}{r+\ell} .
$$

The resistivity change in the nonionized zone is mainly affected by the heat released by the ionization of the soil. The soil resistivity gradually increases as the temperature rises. The current density in the ionized zone is used to characterize the temperature change. The changing state also changes exponentially with time, as shown in (6).

$$
\rho_{2}=\rho_{g} \exp \frac{j}{\tau_{2}},
$$

where $\rho_{2}$ is the soil resistivity in the nonionized zone, $\rho_{g}$ is the initial soil resistivity in the non-ionized zone, and $\tau_{2}$ is the temperature conductivity.

The differential equation of soil resistance in the nonionized zone is shown in the following equation.

$$
d R=\frac{\rho_{2} d r}{2 \pi\left(r^{2}+r \ell\right)}=\frac{\rho_{2} d r}{2 \pi \ell}\left(\frac{1}{r}-\frac{1}{r+\ell}\right) .
$$




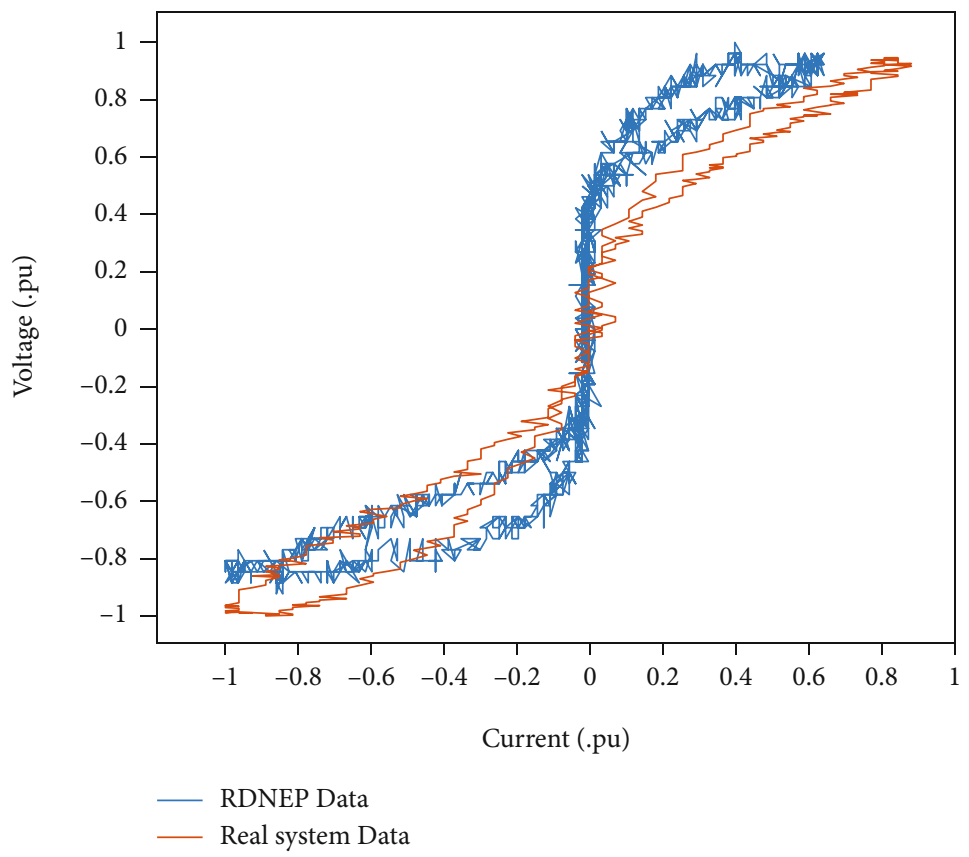

Figure 20: Compare of RDNEP test and RDNS test.

Integrate both sides.

$$
R=\frac{\rho_{2}}{2 \pi \ell}\left(\ln \frac{r+\ell}{r}\right)_{\infty}^{r_{0}} .
$$

As $r \longrightarrow \infty, \ln r+\ell / r \longrightarrow \ln 1=0$, the resistance of the nonionization zone is as in the following equation.

$$
R_{2}=\frac{\rho_{2}}{2 \pi \ell} \ln \frac{r_{0}+\ell}{r_{0}}
$$

The actual grounding resistance of the soil in the grounding process is the sum of the resistance of the ionization zone and the resistance of the nonionization zone, as shown in the following equation.

$$
R=R_{1}+R_{2}=\frac{\rho_{1}}{r+l}+\frac{\rho_{2}}{2 \pi \ell} \ln \frac{r_{0}+\ell}{r_{0}},
$$

where $R$ is SAGF resistance during ionization.

The above description is the arc mathematical model of the soil ionization stage. The ionization process and the deionization process take the moment of the maximum current density as the dividing point. The soil deionization process is similar to the ionization process, but the parameters are different. The ionization process of the negative half cycle is similar to the deionization process, but the current density $j$ is negative, and the current density constant $\tau_{1}$ and temperature conductivity $\tau_{2}$ are opposite to the ionization process.
TABLE 2: SAFG model on RDNEP compared with RDNS.

\begin{tabular}{lcc}
\hline Parameter & RDNEP & RDNS \\
\hline$\rho_{\text {0pii }} / \Omega \mathrm{m}$ & 348 & 226 \\
$\rho_{\text {gpin }} / \Omega \mathrm{m}$ & 373 & 294 \\
$\tau_{1 \text { pii }} /\left(\mathrm{A} / \mathrm{m}^{2}\right)$ & -1822 & -3245 \\
$\tau_{2 p \text { in }} /\left(\mathrm{A} / \mathrm{m}^{2}\right)$ & -18885 & -28918 \\
$\rho_{\text {0pdi }} / \Omega \mathrm{m}$ & 214 & 176 \\
$\rho_{\text {gpdn }} / \Omega \mathrm{m}$ & 219 & 153 \\
$\tau_{1 p d i} /\left(\mathrm{A} / \mathrm{m}^{2}\right)$ & -2792 & -5527 \\
$\tau_{2 p d n} /\left(\mathrm{A} / \mathrm{m}^{2}\right)$ & -54704 & -57971 \\
$\rho_{0 \text { nii }} / \Omega \mathrm{m}$ & 773 & 491 \\
$\rho_{\text {gnin }} / \Omega \mathrm{m}$ & 398 & 236 \\
$\tau_{1 \text { nii }} /\left(\mathrm{A} / \mathrm{m}^{2}\right)$ & 6600 & 3302 \\
$\tau_{2 \text { nin }} /\left(\mathrm{A} / \mathrm{m}^{2}\right)$ & 18681 & 33367 \\
$\rho_{\text {0ndi }} / \Omega \mathrm{m}$ & 183 & 314 \\
$\rho_{\text {gndn }} / \Omega \mathrm{m}$ & 100 & 143 \\
$\tau_{1 \text { ndi }} /\left(\mathrm{A} / \mathrm{m}^{2}\right)$ & 3747 & 3747 \\
$\tau_{2 n d n} /\left(\mathrm{A} / \mathrm{m}^{2}\right)$ & 49652 & 49652 \\
\hline
\end{tabular}

When the current density $j$ is less than the critical value $j_{c}$, the soil does not undergo ionization and is in the arc extinguishing stage. At this period, the soil as a whole presents the characteristics of high resistance. The resistance $R$ $=R_{0}=5000 \Omega$ is used to simulate this high resistance state. 


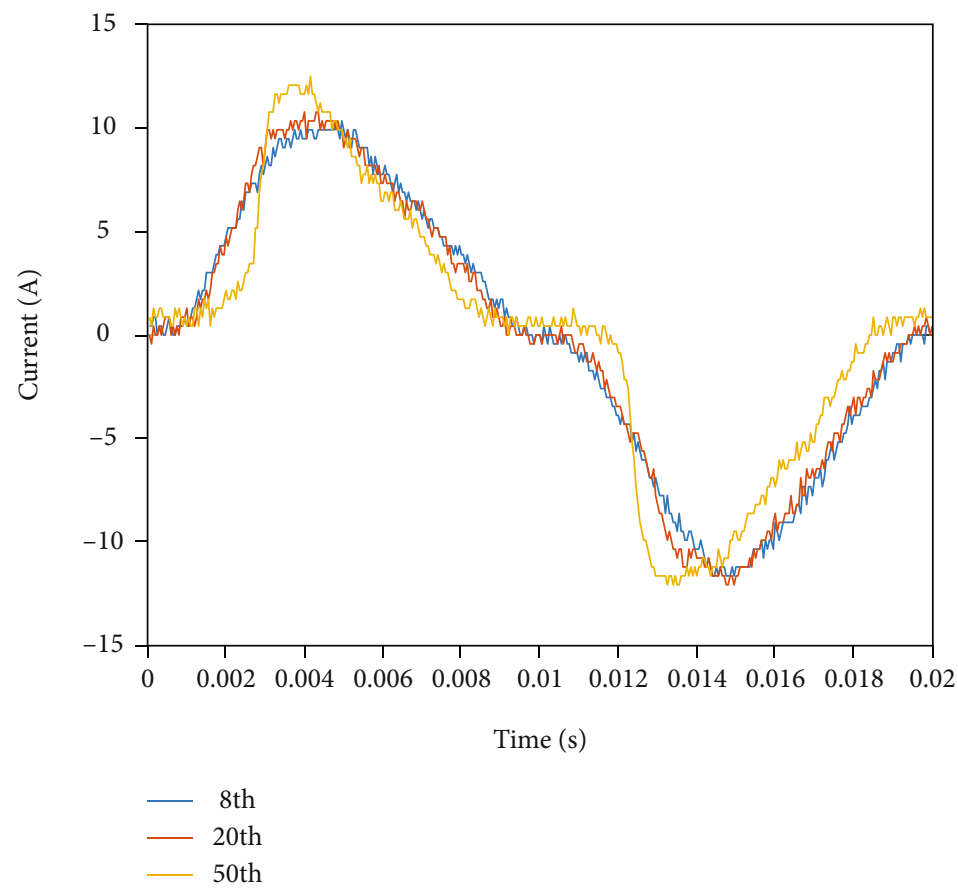

FIgURE 21: Different cycles current curve of a SAFG.

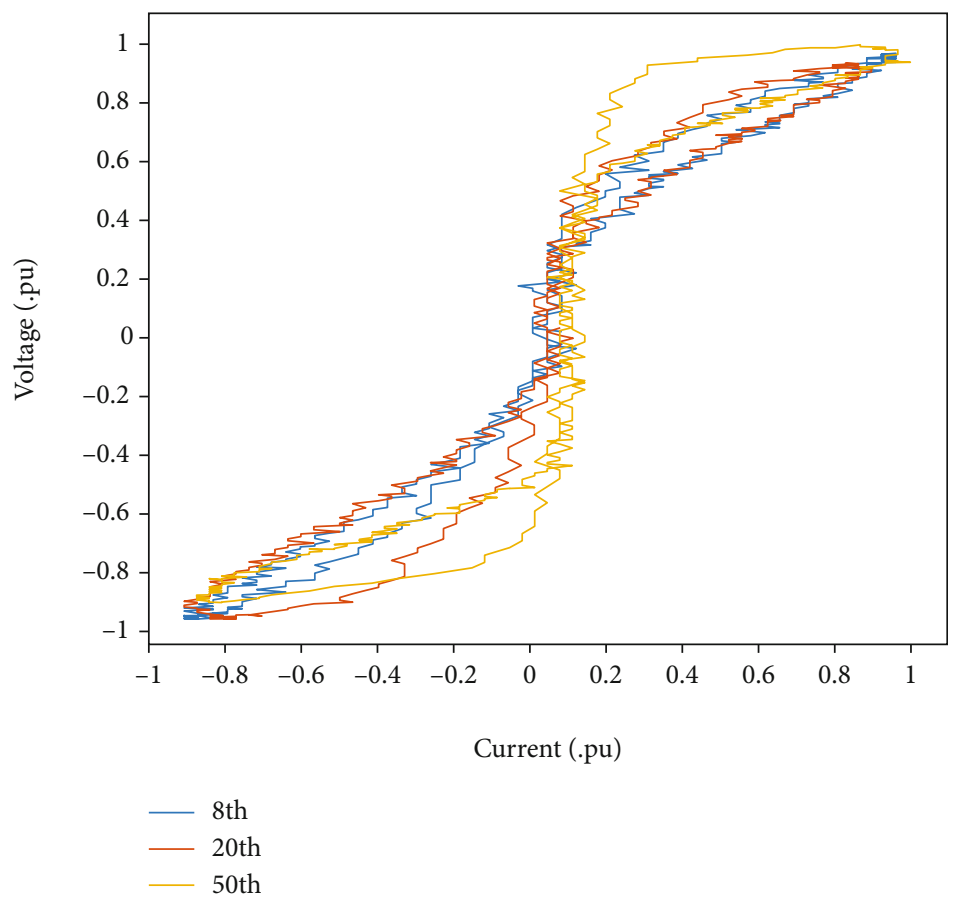

FIgURE 22: Different cycles V/A characteristic of a SAFG.

The SAFG resistance model can be described as the following equation.

$$
\begin{cases}R=R_{0}=5000 \Omega & j<j_{c}, \\ R=R_{1}+R_{2}=\frac{\rho_{1}}{r+l}+\frac{\rho_{2}}{2 \pi \ell} \ln \frac{r_{0}+\ell}{r_{0}} & j \geq j_{c} .\end{cases}
$$

\section{SAGF Numerical Simulation}

In the model, seven parameters need to be determined, the radius of the ionization zone $r_{0}$, the depth of the ionization zone $\ell$, the soil resistivity $\rho_{0}$ at the current density $j=0$ of the ionization zone, the current density constant of the ionization process $\tau_{1}$, the initial soil resistivity of the non- 
TABLE 3: Comparison of model parameters in different circles.

\begin{tabular}{|c|c|c|c|}
\hline Parameter & 8 th & 20th & 50th \\
\hline$\rho_{0 p i i} / \Omega \mathrm{m}$ & 348 & 837 & 495 \\
\hline$\rho_{\mathrm{g} p i n} / \Omega \mathrm{m}$ & 373 & 574 & 426 \\
\hline$\tau_{1 p i i} /\left(\mathrm{A} / \mathrm{m}^{2}\right)$ & -1822 & -966 & -1597 \\
\hline$\tau_{2 p i n} /\left(\mathrm{A} / \mathrm{m}^{2}\right)$ & -18885 & -12178 & -16906 \\
\hline$\rho_{0 p d i} / \Omega \mathrm{m}$ & 214 & 249 & 622 \\
\hline$\rho_{\mathrm{g} p d n} / \Omega \mathrm{m}$ & 219 & 221 & 276 \\
\hline$\tau_{1 p d i} /\left(\mathrm{A} / \mathrm{m}^{2}\right)$ & -2792 & -2691 & -751 \\
\hline$\tau_{2 p d n} /\left(\mathrm{A} / \mathrm{m}^{2}\right)$ & -54704 & -60790 & -31766 \\
\hline$\rho_{0 n i i} / \Omega \mathrm{m}$ & 773 & 1350 & 4177 \\
\hline$\rho_{\mathrm{gnin}} / \Omega \mathrm{m}$ & 398 & 536 & 545 \\
\hline$\tau_{1 n i i} /\left(\mathrm{A} / \mathrm{m}^{2}\right)$ & 6600 & 606 & 371 \\
\hline$\tau_{2 \operatorname{nin}} /\left(\mathrm{A} / \mathrm{m}^{2}\right)$ & 18681 & 13819 & 13466 \\
\hline$\rho_{0 n d i} / \Omega \mathrm{m}$ & 183 & 260 & 219 \\
\hline$\rho_{g n d n} / \Omega m$ & 100 & 242 & 240 \\
\hline$\tau_{1 \text { ndi }} /\left(\mathrm{A} / \mathrm{m}^{2}\right)$ & 3747 & 1800 & 2168 \\
\hline$\tau_{2 n d n} /\left(\mathrm{A} / \mathrm{m}^{2}\right)$ & 49652 & 36140 & 42016 \\
\hline
\end{tabular}

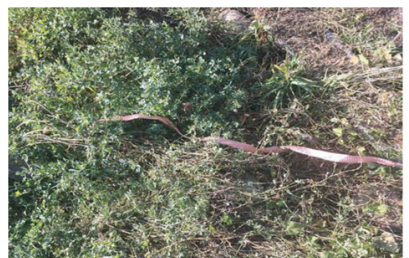

Before fault

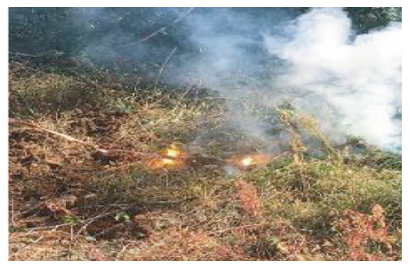

Malfunctioning

FigURE 23: Grounding fault through grassland.

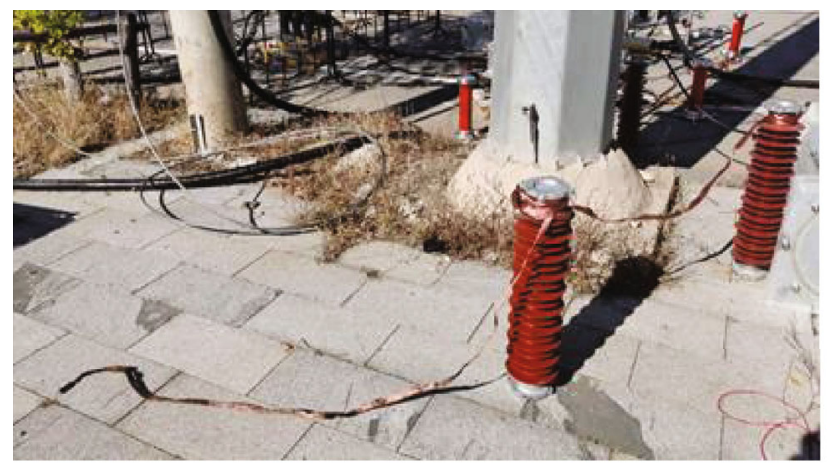

Before fault

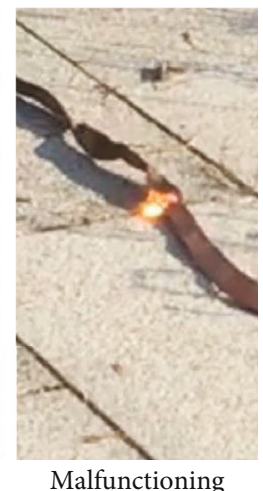

Malfunctioning

Figure 24: Grounding fault through stone road.

ionization zone $\rho_{g}$, the temperature conductivity coefficient $\tau_{2}$, and the ionization criticality current density $j_{c}$.

In this test, a lot of heat is generated after the soil is ionized, the soil will be in a molten state, and $\mathrm{SiO}_{2}$ will be precipitated. After the test, the soil near the grounding point is excavated and sampled. The ionization zone radius is about $0.015 \mathrm{~m}$, and the depth is about $0.15 \mathrm{~m}$. Set the ionization zone parameters $r_{0}=0.015(\mathrm{~m}), \ell=0.15(\mathrm{~m})$.

The positive half-cycle grounding resistance of the soil ionization stage is fitted with the model proposed in this 


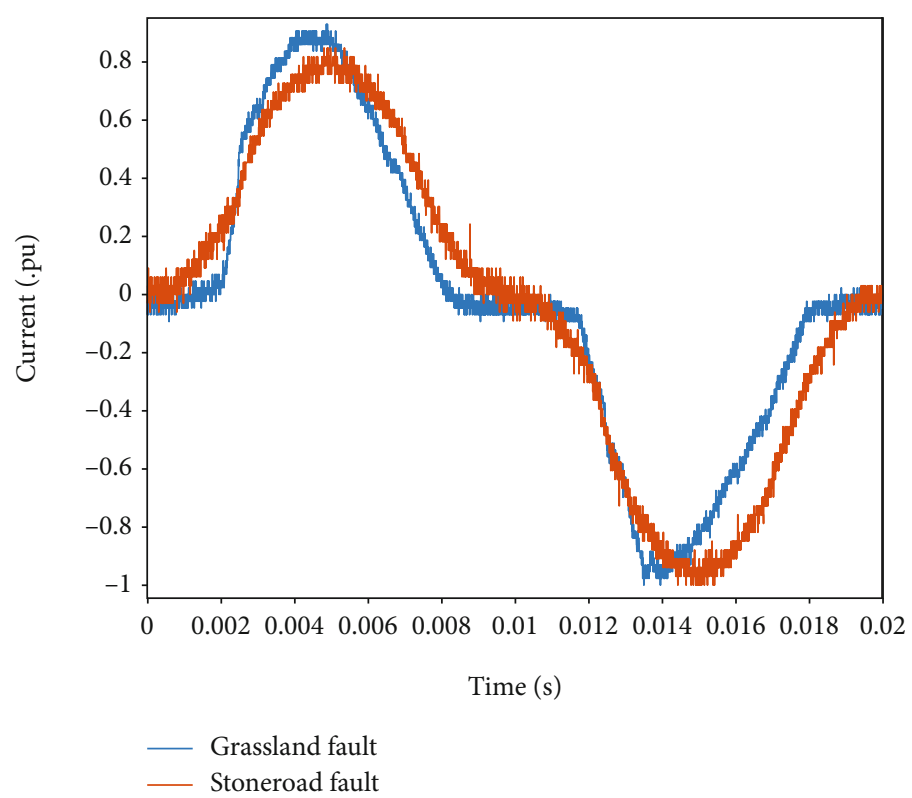

FIGURE 25: Fault current curves of different grounding media.
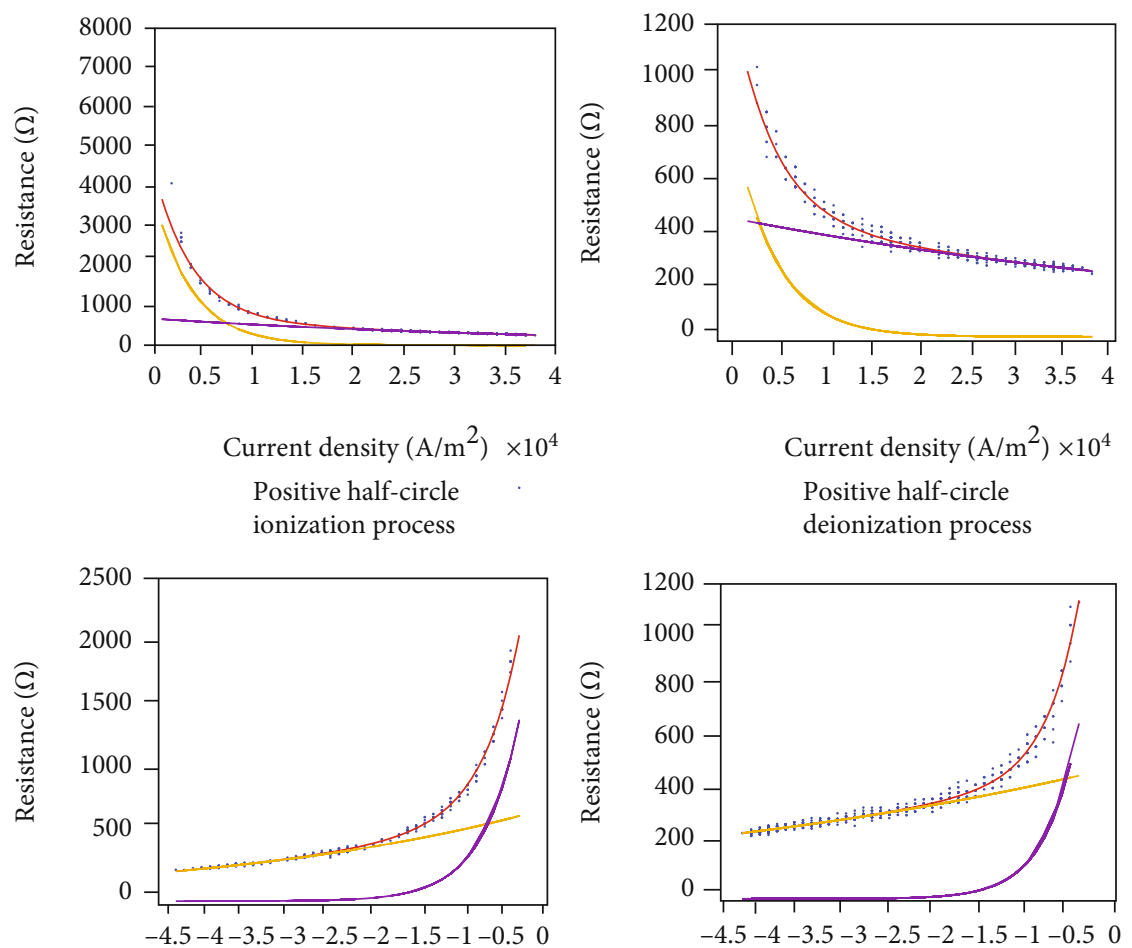

Current density $\left(\mathrm{A} / \mathrm{m}^{2}\right) \times 10^{4}$

Negative half-circle ionization process

$$
\begin{aligned}
& \text { Current density }\left(\mathrm{A} / \mathrm{m}^{2}\right) \\
& \text { Negative half-circle } \\
& \text { deionization process }
\end{aligned}
$$

- Test data

- Model curve

FIGURE 26: Fitting of SAGF model for grassland grounding fault. 

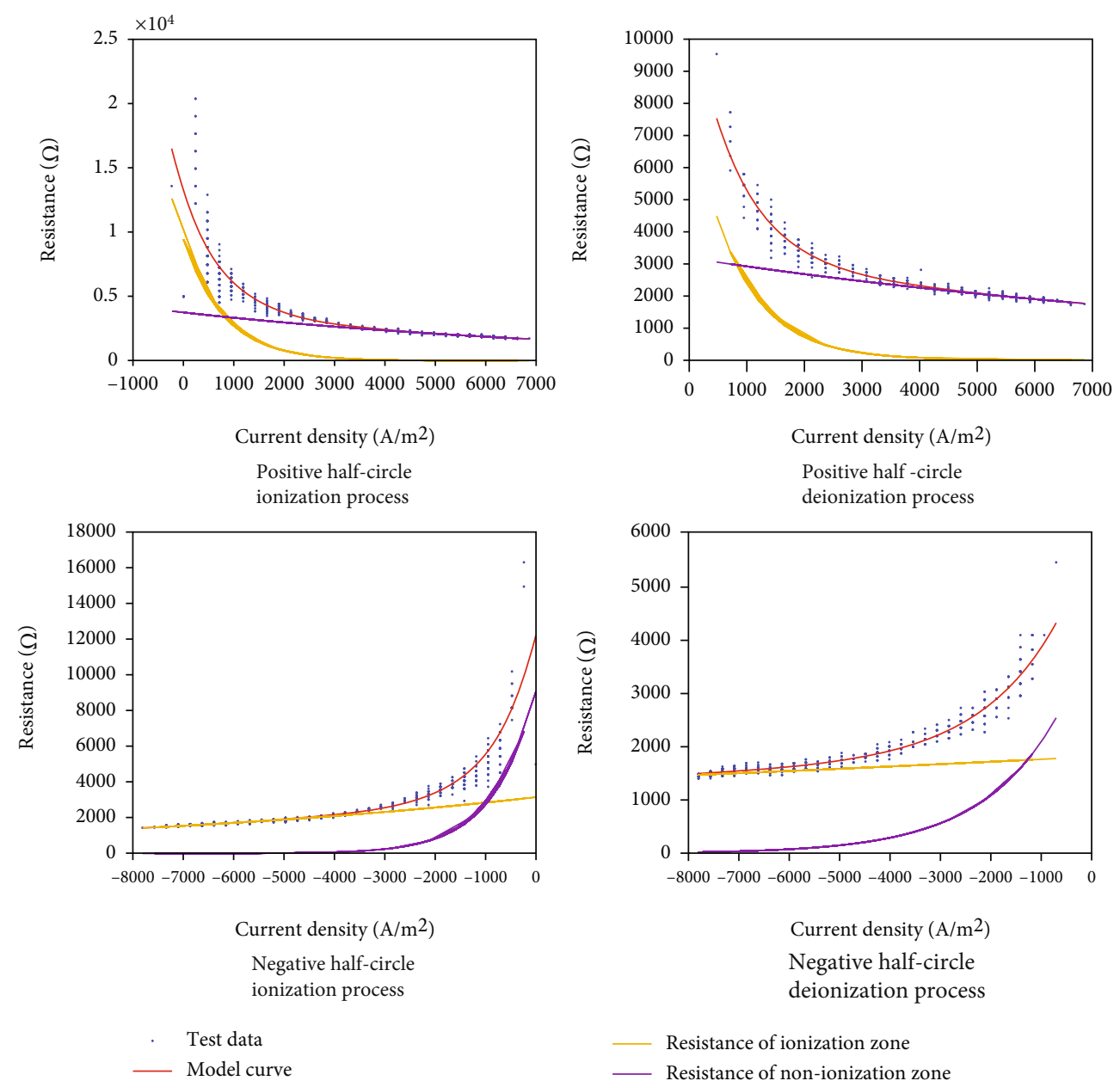

FIGURE 27: Fitting of SAGF model for stone road grounding fault.

paper, the characteristic curve of the fault resistance is corresponding to the current density, and the resistance change curve of the ionization zone and the resistance change curve of the nonionization zone of the model are obtained, as shown in Figures 10 and 11.

In Figure 10, the grounding resistance curve functions as the following equation.

$$
R=2112 \cdot e^{-j / 1822}+951 \cdot e^{-j / 18885} .
$$

The parameters of the positive half-wave ionization process are thus obtained. $\rho_{0}=348 \Omega \cdot m, \rho_{g}=373 \Omega \cdot \mathrm{m}, \tau_{1}=-$ $1822\left(\mathrm{~A} / \mathrm{m}^{2}\right)$, and $\tau_{2}=-18885\left(\mathrm{~A} / \mathrm{m}^{2}\right)$.

The deionization process is shown in Figure 12, and the grounding resistance curve functions as follows.

$$
R=1297 \cdot e^{-j / 2792}+557 \cdot e^{-j / 54704} .
$$

Therefore, $\rho_{0}=214 \Omega \cdot \mathrm{m}, \rho_{g}=219 \Omega \cdot \mathrm{m}, \tau_{1}=-2792(\mathrm{~A} /$ $\left.\mathrm{m}^{2}\right)$, and $\tau_{2}=-54704\left(\mathrm{~A} / \mathrm{m}^{2}\right)$.

Similar to the positive half cycle, the negative half cycle resistance characteristic of the soil ionization stage is shown in Figures 12 and 13.
In the same way, the comparison table of positive and negative half-wave model parameters is shown in Table 1.

Due to the minimum precision voltage and current measurement problem in this experiment, the measured voltage and current data are reliable only when the ground current $i>1(\mathrm{~A})$. Set the critical current density $j_{c}=1 / \pi r_{0}^{2}=$ $1415\left(\mathrm{~A} / \mathrm{m}^{2}\right)$.

Using the above parameters, the arc model proposed in this paper is simulated using PSCAD, and the simulated waveform is compared with the voltage/current obtained in the experiment, as shown in Figures 14 and 15.

The comparison between the simulated waveform and the experimental waveform verifies that the SAGF model proposed in this paper can simulate the development process of the soil arc more accurately, reflecting the characteristics of hysteresis, nonlinearity, and asymmetry of the soil arc. Therefore, the SAGF model is more suitable for describing the SAGF than the commonly used arc models.

\section{Real Distribution Network Verification}

Considering that RDNEP is a realistic distribution network system, in order to verify the credibility of the results measured on the RDNEP, a SAGF was also simulated on a 


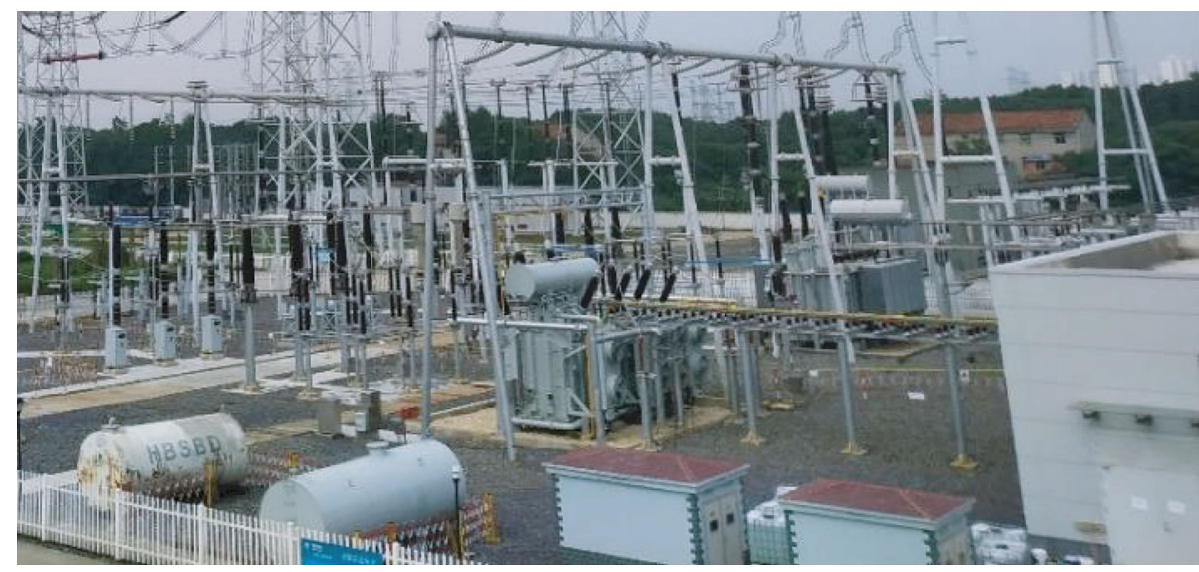

FIGURE 28: Power supply equipment site layout.

RDNS. The grid structure is shown in Figure 16. There are two buses. The bus I runs with 6 feeders. The end of one feeder is used as a grounding point to simulate a SAGF. The bus II runs with 5 feeders, and the system capacitance current is $68 \mathrm{~A}$. In the experiment described in this article, the neutral point is grounded through the arc suppression coil to compensate the inductive current of $47 \mathrm{~A}$, and the theoretical residual current capacity is $21 \mathrm{~A}$.

A $10 \mathrm{kV}$ overhead line ground fault simulation platform is built at the end of the fault simulation feeder, including $10 \mathrm{kV}$ circuit breaker K1, grounding switch T1/T2, low voltage circuit breaker $\mathrm{K} 2$ (replaced with $10 \mathrm{kV}$ pole-mounted circuit breaker), $10 / 0.4 \mathrm{kV}$ transformer (capacity $400 \mathrm{kVA}$ ), and $10 \mathrm{kV}$ drop-out fuse The specific wiring method is shown in Figure 17.

Similar to the RDNEP test, the faulty line is placed on the ground surface through a flat copper wire to simulate the state of the overhead line falling on the ground surface due to a fault. Grounding point after a SAGF test is shown in Figure 18. After the fault occurs, the fault phase voltage and the current waveform through the grounding point are measured, as shown in Figure 19.

In Figure 20, compare V/A characteristics with the RDNEP test. It can be seen that although the V/A characteristic shapes are slightly different, they all satisfy the three soil arc properties mentioned above.

Using the arc waveform measured by the RDNS platform, the parameters of the arc model proposed in this paper are fitted and compared with the RDNEP platform, as shown in Table 2. In order to express clearly and reduce the description, the initial resistivity of the ionization zone in the positive half-cycle ionization process is abbreviated as $\rho_{0 p i i}$, and the initial resistivity of the ionization zone in the positive half-cycle deionization process is abbreviated as $\rho_{0 p d i}$. Other parameters follow such naming rules.

Considering that the soil environment of the RDNEP test and the RDNS test are different, and the fault current is also different, the error of its parameters is acceptable. This proves that the constructed RDNEP can approximate a RDNS, and the SAGF carried out on the RDNEP is also
TABLE 4: Parameters of the transformer.

\begin{tabular}{lc}
\hline Transformer capacity (SN) & $75 \mathrm{MVA}$ \\
\hline Winding 1\# line to line voltage & $230 \mathrm{kV}$ \\
Winding 2\# line to line voltage & $10.5 \mathrm{kV}$ \\
No load losses (P0) & $108.1 \mathrm{~kW}$ \\
Copper losses (Pk) & $155.4 \mathrm{~kW}$ \\
Positive sequence leakage reactance (I0\%) & $0.41 \%$ \\
Short circuit impedance percentage (Uk\%) & $23.9 \%$ \\
\hline
\end{tabular}

credible. Indirectly prove the rationality of the SAGF model proposed in this article.

\section{Time-Based Development of a SAFG}

SAGF is an arc behavior that will not self-extinguish. It will develop dynamically over time, and the development process depends on the soil environment around the fault point.

Compare the arc current curves of the 8th, 20th, and 50th cycles in the RDNEP test, as shown in Figure 21, and the V/A characteristics of different cycles as shown in Figure 22.

As can be seen from the graph, the ionization process of the earth arc becomes faster and faster as time progresses, zero rest time becomes longer, and the deionization speed is basically the same. The waveforms of all cycles conform to the 3 properties of SAGF.

For further comparison, the parameter changes of SAGF models of different periods are shown in Table 3.

Comparing the soil arc parameters of different circles, the following conclusions can be drawn.

(1) The initial soil resistivity in the ionization zone has a large change, while the change of initial soil resistivity in the nonionization zone is little

(2) With the development of time, the current density constant of the ionization zone $\tau_{1}$ will rapidly 


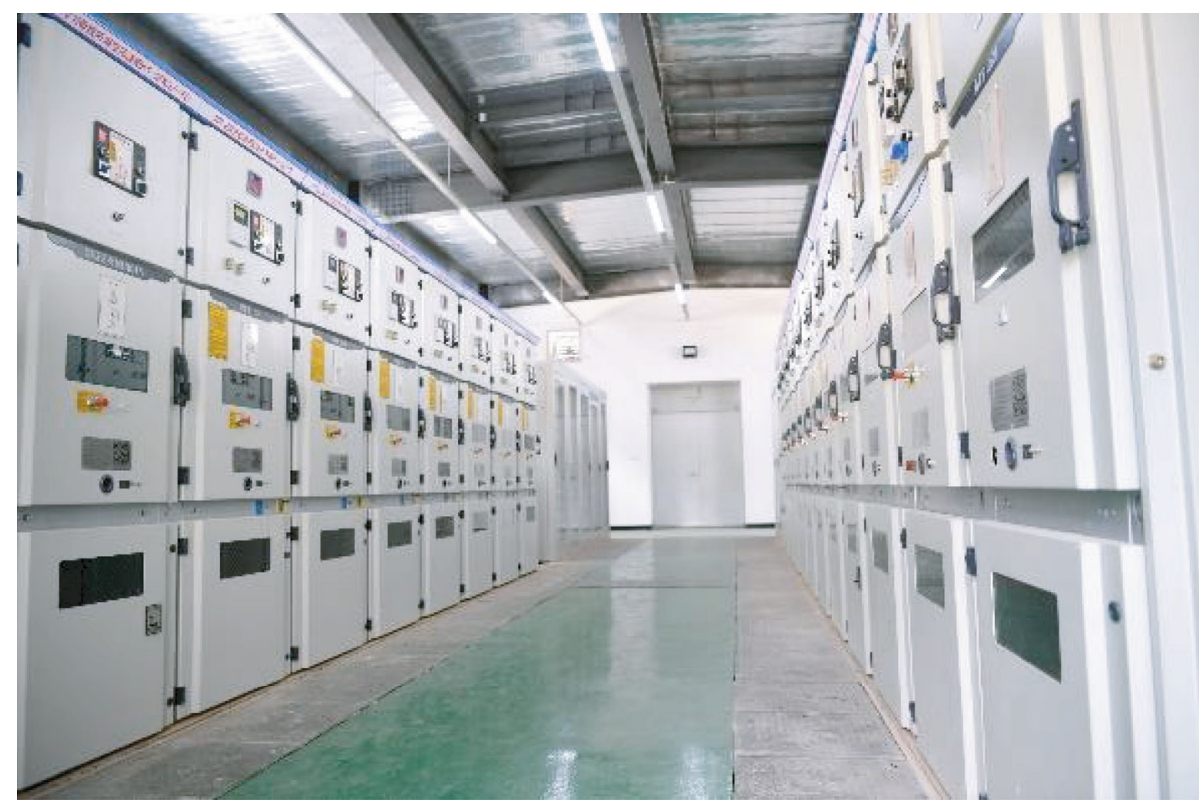

FIgURE 29: Substation.

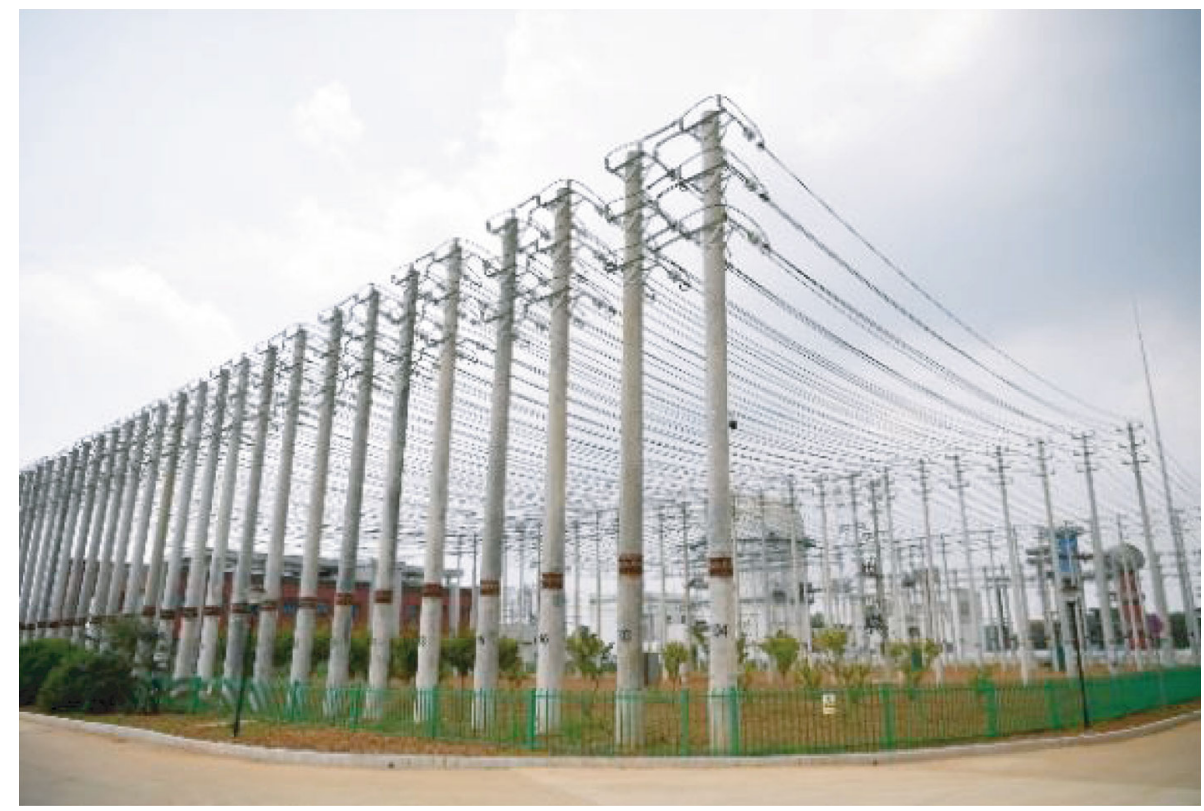

Figure 30: Grid frame.

decrease, which means that the ionization speed becomes faster

(3) The temperature conductivity in the nonionization zone $\tau_{2}$ is basically unchanged, which proves that the soil arc and the heat exchange effect of the nonionization zone are dominant, and the soil properties have not changed

(4) One feature that cannot be reflected in the parameters is that the zero rest time of the arc current is longer

\section{SAGF Model for General Use}

SAGF, as an arc model that specifically refers to the soil, has limited application scope. We hope to develop a general model to describe various forms of high impedance arc grounding faults (HIAF). Therefore, it is necessary to assess the general ability of the SAGF model proposed in this article. The grounding fault through grassland and fault through stone roads is simulated on RDNEP. The test site is shown in Figures 23 and 24. 


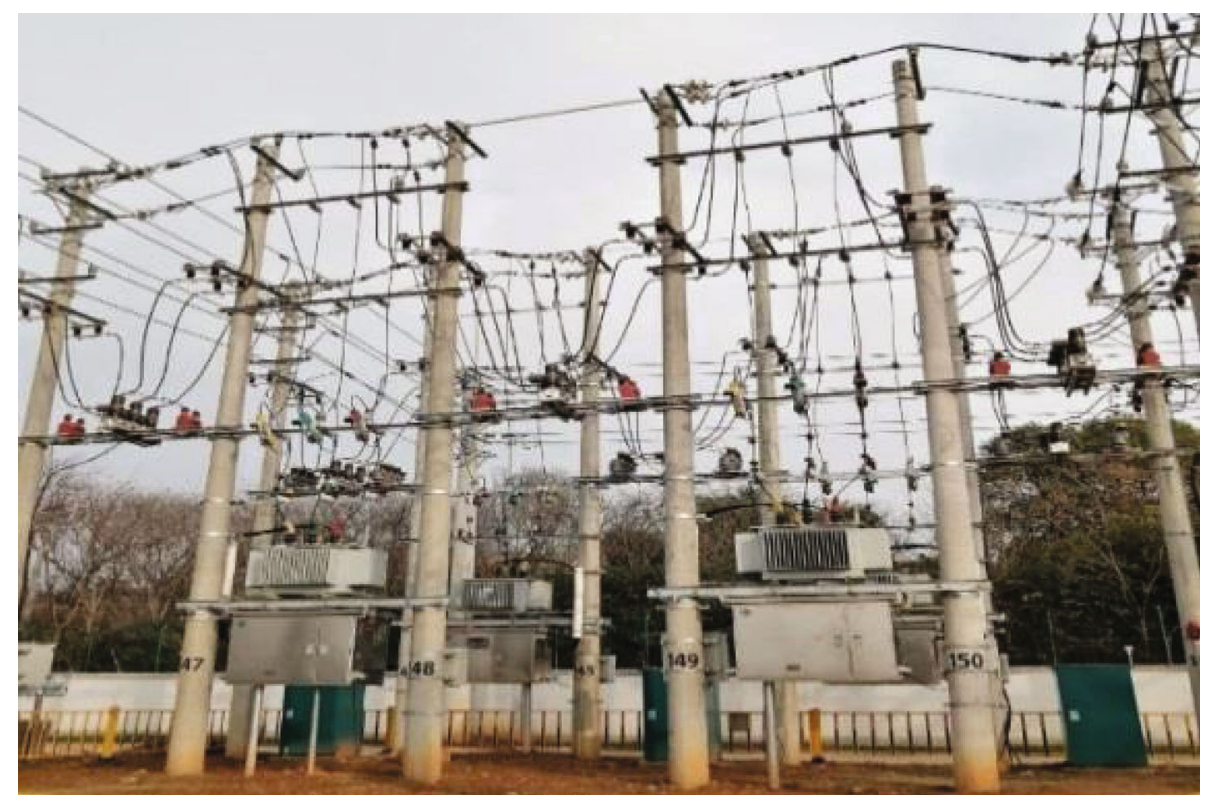

Figure 31: Distribution area.

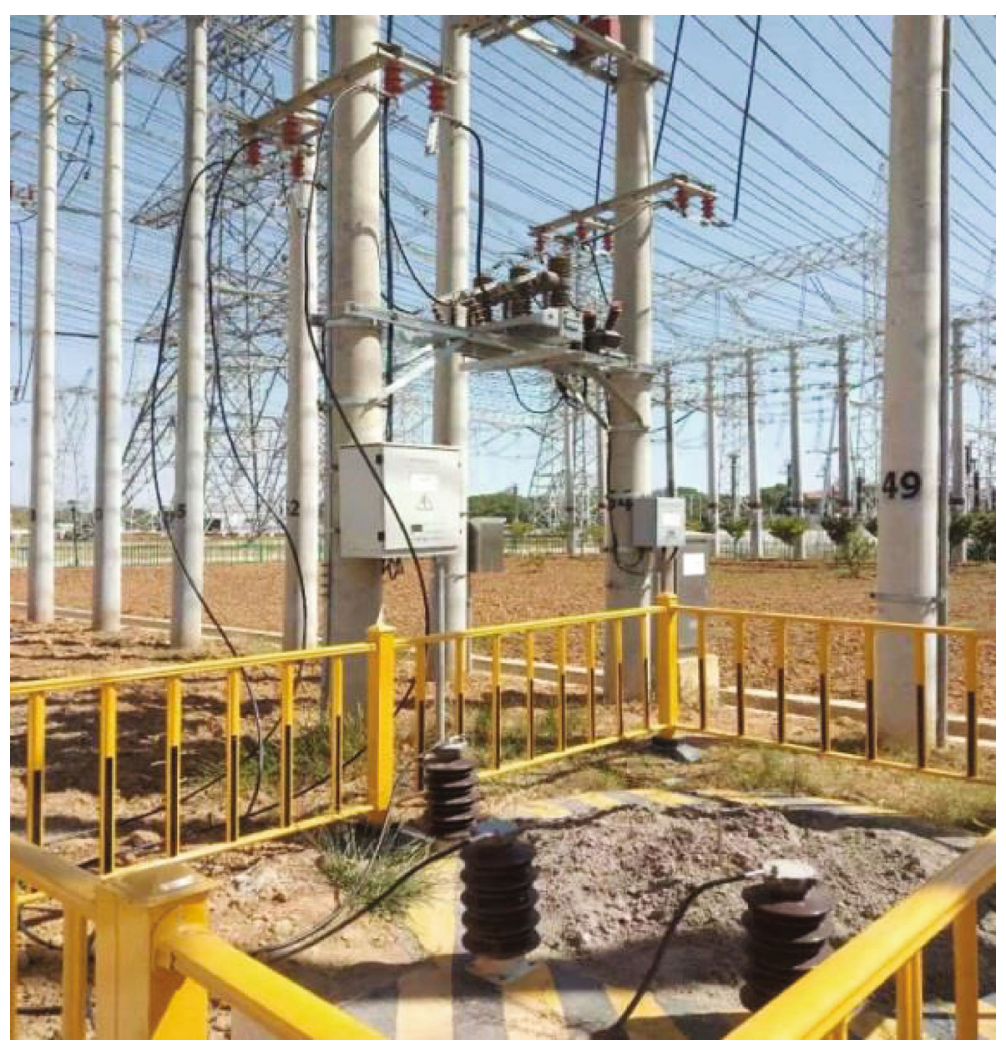

FIGURE 32: One fault simulation area.

Although the above two types of faults are all timedependent developmental, a typical cycle of each type of faults is selected for analysis in this article. The single circle fault current of the two types is shown in Figure 25.

Using the SAGF model proposed in this article, the curve fitting is consistent with the method described above, the fit- ting of SAGF models for each fault is shown in Figures 26 and 27.

The above fitting curve proves that the SAGF model is also suitable for soil-like grounding media. The HIAF with the arc characteristics proposed in this paper can be approximated by SAGF. 


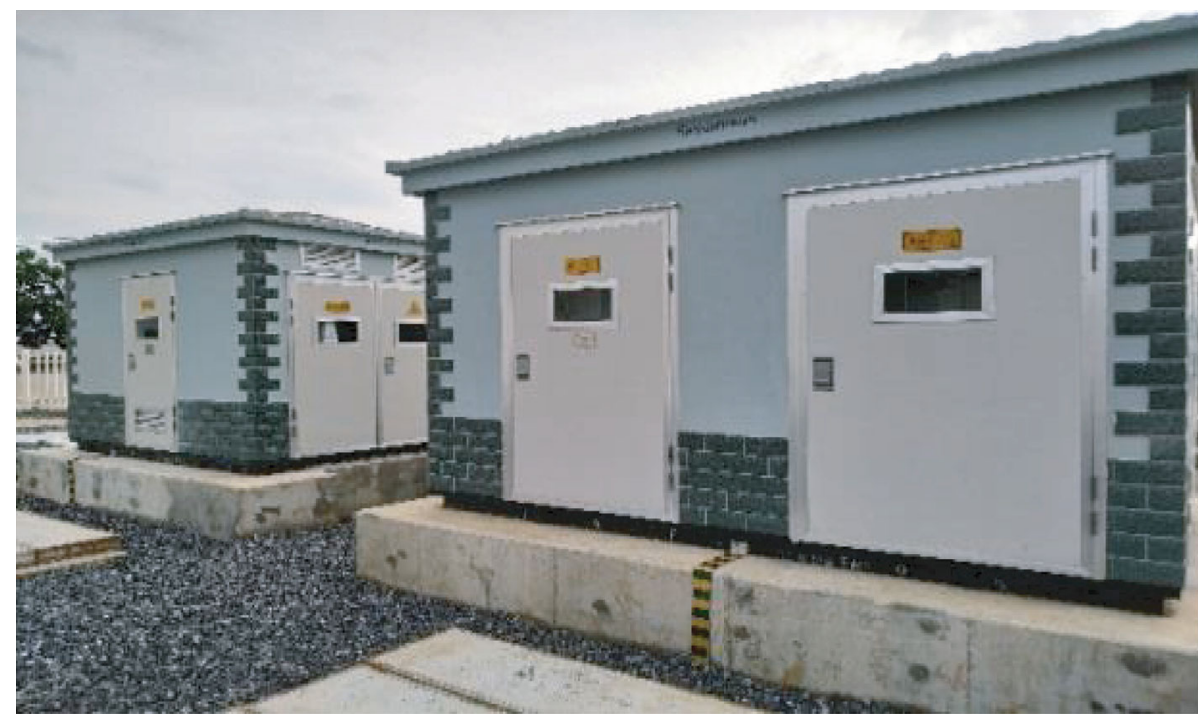

FIGURE 33: Field equipment of neutral grounding device.

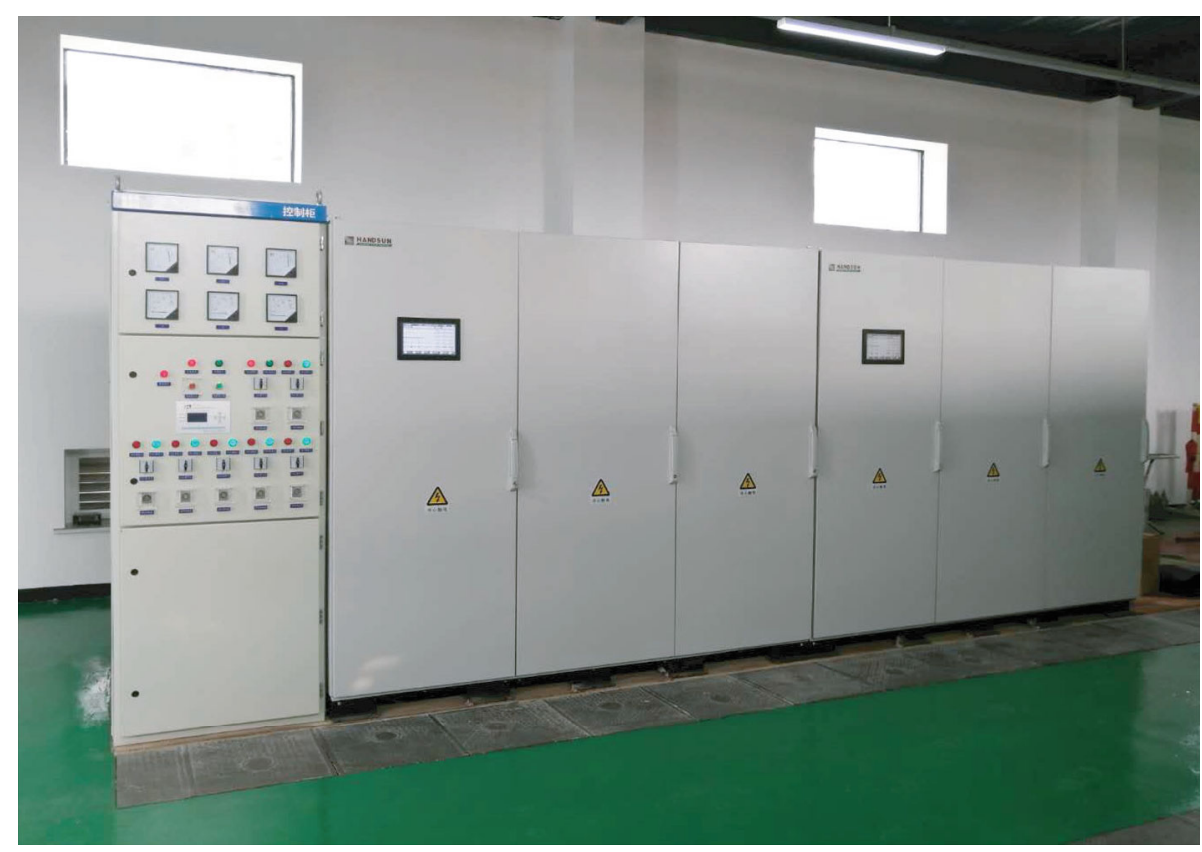

Figure 34: RLC adjustable loads.

\section{Conclusion}

By simulating a SAGF on RDNEP, this paper concludes that the soil arc ground fault has three main characteristics: hysteresis, nonlinearity, and asymmetry. It is pointed out that common arc models are difficult to accurately describe the characteristics of soil arc. On this basis, the idea of dissipating current channels for soil-associated arcs is proposed, and a double exponential function soil arc model based on current density considering ionization and nonionization regions is proposed. Through the comparison of simulation waveforms with experimental data, with the simulation of
SAGF on a RDNS, it is jointly verified that the SAGF numerical simulation method proposed in this paper can simulate the characteristics of soil arc more accurately. On this basis, by adjusting the model parameters, the entire development process of a single-phase soil arc ground fault can be simulated. Furthermore, by studying the applicability of the model proposed in this paper in simulating grassland and stone road grounding faults, it is obtained that the model proposed in this paper has a strong general use ability. The work in this paper laid a theoretical foundation for subsequent research on detection algorithms based on soil arc characteristics. 


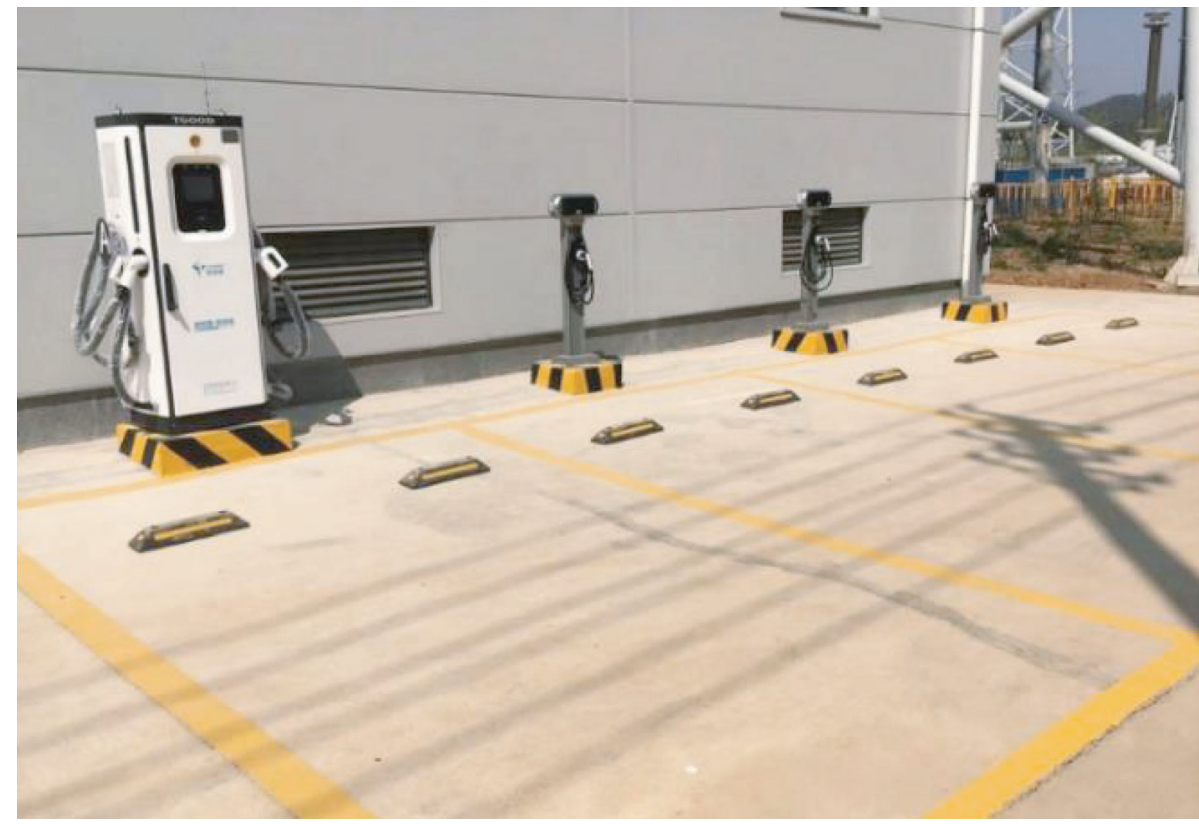

Figure 35: Electric car charging station.

\section{Appendix}

Due to the complexity and dispersion of faults in the distribution network, it is difficult to reproduce faults and measure fault signals. Therefore, CEPRI establishes a RDNEP to simulate failures and evaluate installations. Facilitate scientific research and business activities.

\section{A. Power Supply Equipment}

The RDNEP uses a $220 / 10 \mathrm{kV}$ transformer as the platform power supply. The transformer protection configuration is consistent with the real distribution network. The power supply site layout is shown in Figure 28, and the transformer parameters are shown in Table 4.

\section{B. Power Distribution Equipment}

RDNEP's power distribution equipment mainly includes 2 switch substations, two $3.5 \mathrm{~km}$ real overhead lines, and two $560 \mathrm{~m}$ real cable lines. The substation, feeders, and distribution station areas are shown in Figures 29-31.

There are fault simulation areas under some towers, as in Figure 32. Various ground faults can be simulated at the first, middle, or end of the lines.

A grounding transformer is connected to the bus, and the neutral grounding mode of the system can be switched to nongrounding, resonance grounding, or resistance grounding. Neutral grounding devices are in Figure 33, the resonance grounding device on the left, and the resistance grounding device on the right.

\section{Load Equipment}

RDNEP configures two types of loads, RLC adjustable load and electric car charging station. 2 sets of RLC adjustable loads, each load is three-phase 250kvar, single-phase $85 \mathrm{kvar}$, resistance, inductance, and capacitive loads are continuously adjustable. Equipped with 4 electric vehicle charging piles, 3 slow charging pile and 1 fast-charging pile, the total charging power is $120 \mathrm{~kW}$. As shown in Figures 34 and 35.

\section{Data Availability}

Data sharing not applicable to this article as no datasets were generated or analysed during the current study.

\section{Conflicts of Interest}

The authors declare that they have no conflicts of interest.

\section{Acknowledgments}

This work was supported in part by the State Grid Corporation of China (GY7120003 and 5400-202028111A-0-0-00).

\section{References}

[1] J. C. Gu, Z. J. Huang, J. M. Wang, L. C. Hsu, and M. T. Yang, "High impedance fault detection in overhead distribution feeders using a DSP-based feeder terminal unit," IEEE Transactions on Industry Applications, vol. 57, no. 1, pp. 179-186, 2021.

[2] A. Ghaderi, H. A. Mohammadpour, H. L. Ginn, and Y. J. Shin, "High-impedance fault detection in the distribution network using the time-frequency-based algorithm," IEEE Transactions on Power Delivery, vol. 30, no. 3, pp. 1260-1268, 2015.

[3] F. B. Costa, B. A. Souza, N. S. D. Brito, J. A. C. B. Silva, and W. C. Santos, "Real-time detection of transients induced by high-impedance faults based on the boundary wavelet transform," IEEE Transactions on Industry Applications, vol. 51, no. 6 , pp. 5312-5323, 2015. 
[4] A. Ghaderi, H. L. Ginn III, and H. A. Mohammadpour, "High impedance fault detection: a review," Electric Power Systems Research, vol. 143, pp. 376-388, 2017.

[5] O. Mayr, "Beiträge zur Theorie des statischen und des dynamischen Lichtbogens," Archiv für Elektrotechnik, vol. 37, no. 12 , pp. 588-608, 1943.

[6] A. M. Cassie, Arc Rupture and Circuit Severity: A New Theory, CIGRE report, 1939.

[7] P. H. Schavemaker and L. Van der Slui, "An improved Mayrtype arc model based on current-zero measurements [circuit breakers]," IEEE Transactions on Power Delivery, vol. 15, no. 2, pp. 580-584, 2000.

[8] M. Kizilcay and T. Pniok, "Digital simulation of fault arcs in power systems," European Transactions on Electrical Power, vol. 1, no. 1, pp. 55-60, 1991.

[9] T. Cui, X. Dong, Z. Bo, A. Klimek, and A. Edwards, "Modeling study for high impedance fault detection in MV distribution system," in 2008 43rd International Universities Power Engineering Conference, pp. 1-5, Padua, Italy, 2008.

[10] K. M. Shebl, E. A. Badran, and E. Abdalla, "A combined MODELS-TACS ATPdraw general model of the high impedance faults in distribution networks," MEPCON, vol. 10, pp. 19-21, 2010.

[11] W. Bin, G. Jianzhao, and D. Xinzhou, "High-impedance fault modeling based on solid dielectric electrical breakdown theory," Automation of Electric Power Systems, vol. 38, no. 12, pp. 62-66, 2014.

[12] A. E. Emanuel, D. Cyganski, J. A. Orr, S. Shiller, and E. M. Gulachenski, "High impedance fault arcing on sandy soil in $15 \mathrm{kV}$ distribution feeders: contributions to the evaluation of the low frequency spectrum," IEEE Transactions on Power Delivery, vol. 5, no. 2, pp. 676-686, 1990.

[13] A. Sharat, L. Snider, and K. Debnath, "A neural network based back error propagation relay algorithm for distribution system high impedance fault detection," in 1993 2nd international conference on advances in power system control, Operation and Management, APSCOM-93, vol. 2, pp. 613-620, Hong Kong, 1993.

[14] David Chan Tat Wai and Xia Yibin, "A novel technique for high impedance fault identification," IEEE Transactions on Power Delivery, vol. 13, no. 3, pp. 738-744, 1998.

[15] Y. Sheng and S. M. Rovnyak, "Decision tree-based methodology for high impedance fault detection," IEEE Transactions on Power Delivery, vol. 19, no. 2, pp. 533-536, 2004.

[16] T. Lai, L. Snider, and E. Lo, "Wavelet transform based relay algorithm for the detection of stochastic high impedance faults," Electric Power Systems Research, vol. 76, no. 8, pp. 626-633, 2006.

[17] R. G. Ferraz, L. U. Iurinic, A. D. Filomena, D. S. Gazzana, and A. S. Bretas, "Arc fault location: a nonlinear time varying fault model and frequency domain parameter estimation approach," International Journal of Electrical Power \& Energy Systems, vol. 80, pp. 347-355, 2016.

[18] S. R. Nam, J. K. Park, Y. C. Kang, and T. H. Kim, “A modeling method of a high impedance fault in a distribution system using two series time-varying resistances in EMTP," in 2001 Power Engineering Society Summer Meeting. Conference Proceedings (Cat. No. 01CH37262), vol. 2, pp. 1175-1180, Vancouver, BC, Canada, 2001. 